Article

\title{
Soft Sensors in the Primary Aluminum Production Process Based on Neural Networks Using Clustering Methods
}

\author{
Alan Marcel Fernandes de Souza ${ }^{1, *}$, Fábio Mendes Soares ${ }^{1}$, Marcos Antonio Gomes de Castro ${ }^{2}$, \\ Nilton Freixo Nagem ${ }^{3}$, Afonso Henrique de Jesus Bitencourt ${ }^{4}$, Carolina de Mattos Affonso ${ }^{1}$ and \\ Roberto Célio Limão de Oliveira ${ }^{1}$ (1) \\ 1 Institute of Technology, University of Pará, Belém 66075-110, Brazil; fms@ufpa.br (F.M.S.); \\ carolina@ufpa.br (C.d.M.A.); limao@ufpa.br (R.C.L.d.O.) \\ 2 Department of Automation, Specialist Engineer, Aluminum of Brazil (ALBRAS), Barcarena 68445-000, Brazil; \\ marcos.castro@albras.net \\ 3 Reduction Area, Process Engineering Manager, Aluminum of Brazil (ALBRAS), Barcarena 68445-000, Brazil; \\ nilton.nagem@albras.net \\ 4 Department of Automation, Manager of Energy, Utilities, Automation, and Predictive, Aluminum of \\ Brazil (ALBRAS), Barcarena 68445-000, Brazil; afonso.bitencourt@albras.net \\ * Correspondence: alanmarcel2@gmail.com
}

Received: 9 September 2019; Accepted: 22 October 2019; Published: 29 November 2019

\begin{abstract}
Primary aluminum production is an uninterrupted and complex process that must operate in a closed loop, hindering possibilities for experiments to improve production. In this sense, it is important to have ways to simulate this process computationally without acting directly on the plant, since such direct intervention could be dangerous, expensive, and time-consuming. This problem is addressed in this paper by combining real data, the artificial neural network technique, and clustering methods to create soft sensors to estimate the temperature, the aluminum fluoride percentage in the electrolytic bath, and the level of metal of aluminum reduction cells (pots). An innovative strategy is used to split the entire dataset by section and lifespan of pots with automatic clustering for soft sensors. The soft sensors created by this methodology have small estimation mean squared error with high generalization power. Results demonstrate the effectiveness and feasibility of the proposed approach to soft sensors in the aluminum industry that may improve process control and save resources.
\end{abstract}

Keywords: primary aluminum production; soft sensor; neural network; real data; estimation; clustering methods

\section{Introduction}

Although pure aluminum (Al) is one of nature's most abundant elements, it is extremely difficult to extract, and extraction is not possible without the occurrence of some chemical reaction. Al is always attached to some other chemical element in the form of salts or oxides, which makes separation necessary. In the 1880s, the young students Charles Hall and Paul Héroult used electrolysis to separate the $\mathrm{Al}$ of oxygen from alumina $\left(\mathrm{Al}_{2} \mathrm{O}_{3}\right)$ grains into salts fluxes such as cryolite $\left(\mathrm{Na}_{3} \mathrm{AlF}_{6}\right)$. This is the Hall-Héroult process [1,2] by which the primary aluminum industries perform can obtain Al up to $99.9 \%$ purity. Basically, this is the separation of alumina into alumina and oxygen, but the process also requires the participation of other elements such as flux salts, gases, and chemical additives to maintain process stability, which makes the process more complex $[1,3]$. 
For complex industrial processes, mathematical modeling is also a complex task, in such a way that representing a process in a completely analytical way becomes impracticable. The use of approximate and hybrid representations produces very satisfactory results, although they are not scalable from a certain point [4]. As the scientific improvement of modeling and identification techniques [5], this task has been dealt with more easily and in various areas of knowledge, although the great difficulty of performing dynamic modeling of nonlinear processes remains.

This process of modeling and identification of dynamic nonlinear systems has advanced considerably with the use of artificial intelligence and machine learning techniques, which have been applied in the last few decades with excellent results [6-10]. The success of using these "intelligent" paradigms in modeling dynamic systems is due to the little knowledge required to perform modeling (only a reasonable amount of data is required) compared to other forms of analytical modeling, and also because they are naturally nonlinear models. Among these "intelligent" techniques used for nonlinear dynamic modeling [11,12], one of the most used is artificial neural networks. The use of artificial intelligence in dynamic modeling based on data is sometimes referred to as soft sensors.

Soft sensors are computationally implemented, data-driven models that provide online estimates of process variables that cannot be continuously and/or reliably measured online for technological and/or economic reasons $[4,13]$. These techniques use process variables that are measured and recorded reliably online using available physical sensors or offline through laboratory analysis results.

Data-driven soft sensors have wide success in the industry, because of its practicability, robustness, and flexibility to be developed and applied to a wide range of processes, in addition to their independence from a process mathematical model $[14,15]$. There are a number of methods for implementing flexible data-driven sensors for industrial processes. Some of the most commonly used linear methods are multi-statistic regression algorithms, such as principal component analysis (PCA) [16-19] and partial least squares (PLS) [20-23]. These methods have more practical applications because of their simplicity and can work with some invariance in time; however, they have some disadvantages because they are prone to errors in the presence of data impurities (missing values and outliers) and are inadequate to deal with nonlinearities.

Nonlinear processes are usually modeled with nonlinear structures such as artificial neural networks (ANN) [24-28], neuro-fuzzy [29-31], Gaussian process regression support vectors [32-34], and support vector machines [35-37]. The most common types of ANN are multi-layer perceptron (MLP) and radial basis function networks (RBFN). The literature has shown that ANN is especially suitable for implementation of soft sensors, and these have indeed been used [38-47]. More recently, deep learning has been used to create soft sensors also successfully [48-51].

Due to the complexity of the primary aluminum production process, it is interesting to use data-driven soft sensors to measure the most important variables of this process, since it is a nonlinear, time-variant, and distributed-parameter dynamic process. Moreover, since the electrolytic process of oxidized alumina reduction is very aggressive, it is not possible to have temperature measurements in real time, since the chemical bath corrodes the thermocouple (usually a thermocouple can do 50 measurements every $24 \mathrm{~h}$ ).

ANNs have been used as a powerful artificial intelligence technique to construct models based on data in the Al industry [52-55]. In this way, ANNs are also widely used to implement soft sensors. In the Al smelting process, ANN has been used in a minor way to simulate and model processes [56-58], while in parallel other techniques like clustering help to identify pots with common behaviors to enhance the knowledge derived from the data [59]. In major part, mathematical techniques have been used to create models to emulate the Al production process [60-64].

An industrial Al plant has hundreds of pots working simultaneously, so this feature contributes to make the production process more complex as a whole, often requiring many human interventions [3]. Methodologically, it is possible to apply neural modeling in one of the following approaches:

- A single ANN for all electrolysis pots; in this approach, the results are barely satisfactory, since it is very difficult for ANN to capture the behavioral differences of all pots. 
- An ANN for each pot, which might be too complex and difficult to apply, since it is necessary to tune hundreds of ANNs.

- One ANN for a certain cluster of pots, which present similar behaviors.

This paper describes the process of designing soft sensors using the third methodology, which could present the best trade-off between complexity and quality of results. The engineering expertise is useful for determining the key process variables to include, and the ANN technique helps in variable indirect estimation within electrolytic bath furnace modeling using real data from an $\mathrm{Al}$ smelter plant. This paper's major contributions are as follows: clustering data by pots section; considering three different phases of pots, based on lifespan division; and comparing and proposing neural network estimators as soft sensors to replace manual measurements with automatic. The results show this is possible, since the models generate estimations with small errors. It is important to highlight ANN models created are dynamic, because delayed inputs were considered to estimate the current outputs. Briefly, the flowchart of the proposed method is presented by Figure 1.

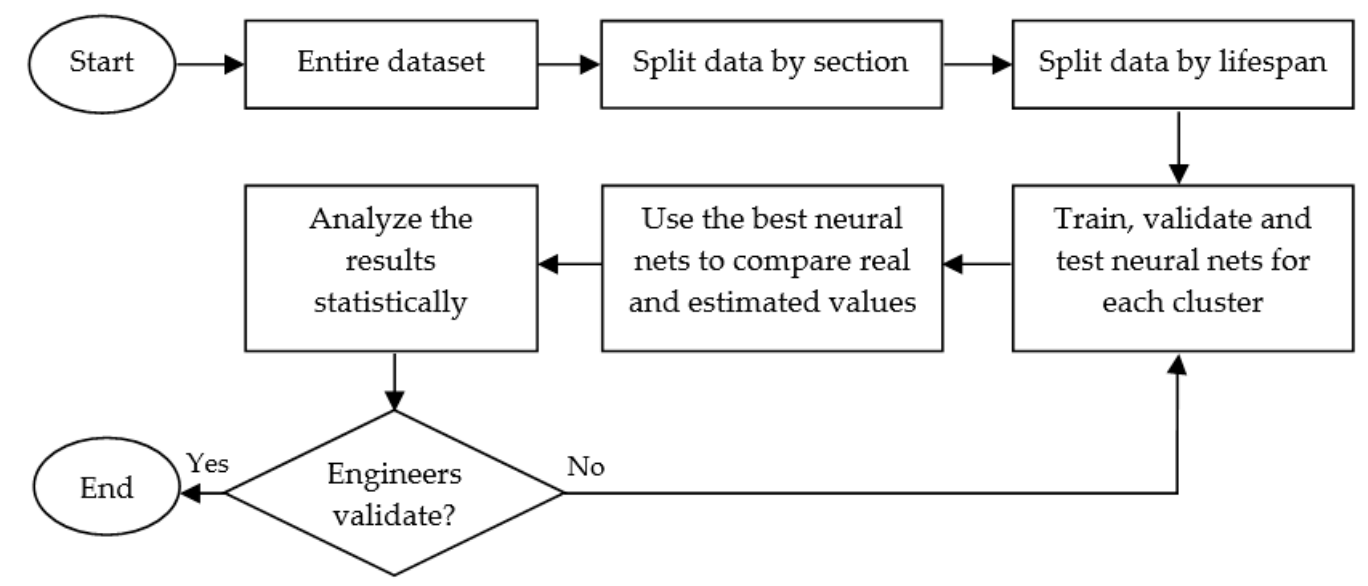

Figure 1. Flowchart of the proposed method.

The rest of this work is organized as follows. Section 2 describes the primary Al production process and describes the layout of the $\mathrm{Al}$ smelter concerned in this paper. Section 3 addresses in detail the design of the ANN-based estimation models. Results and discussions are presented in Section 4. Finally, Section 5 provides the conclusions.

\section{Brief Description of the Primary Aluminum Production Process}

Softness, lightness, high thermal conductivity, and high recyclability are important properties of Al. A wide variety of products are derived from this metal, which has helped it to become the most frequently consumed nonferrous metal around the world [64]. The primary Al production process is complex, due to the handling of variables from multiple disciplines, such as electrical, chemical, and physical [65].

The raw material of $\mathrm{Al}$ is alumina. Direct $\mathrm{Al}$ extraction from alumina requires a temperature over $2000{ }^{\circ} \mathrm{C}$ [66]. The machinery to maintain this high temperature is expensive, and so is the energy waste under these requirements. From the late nineteenth century, the Hall-Héroult process has been used as an alternative to produce $\mathrm{Al}$, as it consumes less energy and requires a lower temperature (about $960^{\circ} \mathrm{C}$ ) [1-3]. To reduce the heat, cryolite is used as an electrolytic bath and several chemical components are added together with alumina [67].

This process is widely known as $\mathrm{Al}$ smelting, which uses electrolysis pots, also named pots or reduction pots [68]. A pot (Figure 2) consists of a steel shell with a lining of fireclay brick for heat insulation, which, in turn, is lined with carbon bricks to hold the molten electrolyte. Steel bars carry the electric current through the insulating bricks into the carbon cathode floor of the pot. Carbon 
anode blocks are hooked onto steel rods and immersed in the electrolyte. Alumina molecules are dissolved by the heat and decomposed into $\mathrm{Al}$ and oxygen $(\mathrm{O})$ by electric current that flows through the electrolyte [69]. In modern smelters, process-control computers connected to remote sensors ensure optimal operation of electrolysis pots [70]. Electrolysis furnaces are organized within reduction rooms-standard Al smelting uses around four reduction rooms and between 900 and 1200 pots in total, depending on the smelter.

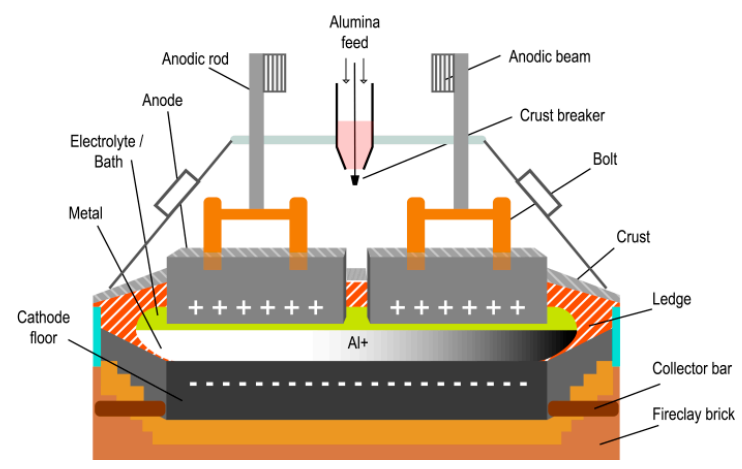

Figure 2. Example of a pot and its parts.

According to the stoichiometric relation (Equation (1)), alumina is consumed in the production process together with the solid carbon of the anodes. Theoretically, this consumption is $1.89 \mathrm{~kg}$ of $\mathrm{Al}_{2} \mathrm{O}_{3}$ for each $1.00 \mathrm{~kg}$ of $\mathrm{Al}^{+}$, whereas $0.33 \mathrm{~kg}$ of carbon $\left(\mathrm{C}^{+}\right)$produces $1.22 \mathrm{~kg}$ of carbon dioxide $\left(\mathrm{CO}_{2}\right)$. In practice, typical values are $1.93 \mathrm{~kg} \mathrm{Al} \mathrm{O}_{3}$ to $1.00 \mathrm{~kg} \mathrm{Al}{ }^{+}$and between 0.40 and $0.45 \mathrm{~kg}^{\circ} \mathrm{C}^{+}$ to $1.00 \mathrm{~kg} \mathrm{Al}^{+}$, with an emission of about $1.50 \mathrm{~kg} \mathrm{CO}_{2}$ [69].

$$
2 \mathrm{Al}_{2} \mathrm{O}_{3}(\text { dissolved })+3 \mathrm{C}+(\text { solid })=>4 \mathrm{Al}+(\text { liquid })+3 \mathrm{CO}_{2}(\text { gas }) .
$$

Several sensors monitor the entire process continuously, acquiring data from the entire plant. Data are stored and organized in databases, which became a rich patrimony of the plants, as they keep the historical information on each production pot. This data collection supports the building of automatic decision-making systems and guides for the engineers [71-74]. Many control systems display the data acquired in real time for the permanent monitoring of the process. Plant control systems for $\mathrm{Al}$ smelting have two modes of operation [74,75]:

- $\quad$ Automatic control: Data are collected and processed by computers and/or microcontrollers, which then drive a control action on the plant without direct human intervention. Examples: control of electrical resistance of the pot by the anode-cathode distance (ACD) using pulse width modulation (PWM) to drive the lifting/lowering of anodes; and the control of alumina to be added to the electrolytic bath through mathematical models.

- Manual control: Data are collected through plant floor sensors or manually measured by process operators, but the calculation of the output is performed by the process engineers, taking into account mathematical models and their expertise. Examples: thermocouple to measure the temperature of the pots (Figure 3), percentage of fluoride alumina in the bath (laboratory result), metal level of the pot, replacement of anodes, and Al tapping from the pot. 


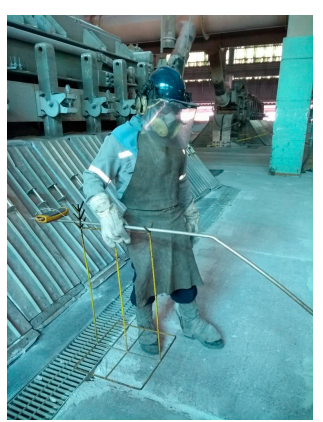

(a)

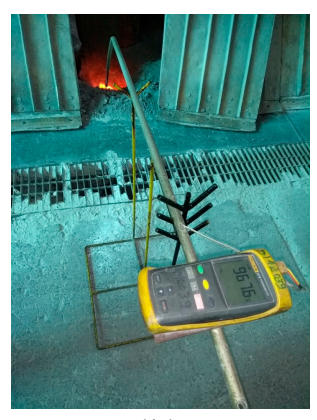

(b)

Figure 3. Pot temperature measurement: (a) human operator; and (b) thermocouple connected to display the temperature value.

The experiments conducted in this paper were derived from a real Brazilian Al smelter, from which real data were used to generate results. The pots are arranged in four reductions, each of which has two rooms, and each room has 120 pots, resulting in 960 pots. Figure 4 shows the overall layout of this factory.

\begin{tabular}{|c|c|c|c|c|c|c|c|c|c|}
\hline \multicolumn{10}{|c|}{ Reduction I } \\
\hline \multicolumn{10}{|c|}{ Room 1} \\
\hline 1 & 2 & 3 & 4 & 5 & 6 & 7 & 8 & $\ldots$ & 120 \\
\hline \multicolumn{10}{|c|}{ Room 2} \\
\hline 121 & 122 & 123 & 124 & 125 & 126 & 127 & 128 & $\ldots$ & 240 \\
\hline \multicolumn{10}{|c|}{ Reduction II } \\
\hline \multicolumn{10}{|c|}{ Room 3} \\
\hline 241 & 242 & 243 & 244 & 245 & 246 & 247 & 248 & $\ldots$ & 360 \\
\hline \multicolumn{10}{|c|}{ Room 4} \\
\hline 361 & 362 & 363 & 364 & 365 & 366 & 367 & 368 & $\ldots$ & 480 \\
\hline \multicolumn{10}{|c|}{ Reduction III } \\
\hline \multicolumn{10}{|c|}{ Room 5} \\
\hline 481 & 482 & 483 & 484 & 485 & 486 & 487 & 488 & $\ldots$ & 600 \\
\hline \multicolumn{10}{|c|}{ Room 6} \\
\hline 601 & 602 & 603 & 604 & 605 & 606 & 607 & 608 & $\ldots$ & 720 \\
\hline \multicolumn{10}{|c|}{ Reduction IV } \\
\hline \multicolumn{10}{|c|}{ Room 7} \\
\hline 721 & 722 & 723 & 724 & 725 & 726 & 727 & 728 & $\ldots$ & 840 \\
\hline \multicolumn{10}{|c|}{ Room 8} \\
\hline 841 & 842 & 843 & 844 & 845 & 846 & 847 & 848 & $\ldots$ & 960 \\
\hline
\end{tabular}

Figure 4. Overall layout of the smelter made up of four reductions, eight rooms, and 960 pots. 
Electrically, $\mathrm{Al}$ reduction pots are connected in series. This connection allows the continuous electric current (approximately $180 \mathrm{kA}$ ) to be the same in all pots. It should be noted that for a room there are two lines of electricity, each line composed of two sections, which in turn contain 30 pots, resulting in 32 different sections for the entire smelter. Figure 5 outlines the arrangement of the sections for reduction I and the first room. This same organization is present in all rooms of the smelter concerned and these pots' disposition was used as clusters empirically; each cluster is a section.

\begin{tabular}{|c|c|c|c|c|c|c|c|c|c|c|c|}
\hline \multicolumn{12}{|l|}{ Reduction I } \\
\hline \multicolumn{12}{|c|}{ Room 1} \\
\hline \multicolumn{3}{|c|}{ Section 1.1} & \multicolumn{3}{|c|}{ Section 1.2} & \multicolumn{3}{|c|}{ Section 1.3} & \multicolumn{3}{|c|}{ Section 1.4} \\
\hline 1 & $\ldots$ & 30 & 31 & $\ldots$ & 60 & 61 & $\ldots$ & 90 & 91 & $\ldots$ & 120 \\
\hline
\end{tabular}

Figure 5. Section layout by room.

\section{Design of Estimation Models}

The full database has hundreds of thousands of samples and hundreds of process features (variables) from 2006 to 2016. The following subsection depicts the preprocessing steps performed in the original database in order to generate the datasets used in this work.

\subsection{Data Extraction, Imputation, and Split}

Data extraction considered the entire life of each pot, in other words a lifespan from 1 to 1500 days, taking into account an average of five years of operation. Table 1 shows all variables available in the database. Therefore, features selection considered Pearson correlation (R), between input and output, to rank variables by degree of importance. It is important to know that some variables have a large number of null values, so they were discarded. $\mathrm{R}$ is calculated as:

$$
R_{x y}=\frac{\sum_{\mathrm{i}=1}^{\mathrm{n}}\left(x_{i}-\bar{x}\right)\left(y_{i}-\bar{y}\right)}{\sqrt{\sum_{\mathrm{i}=1}^{\mathrm{n}}\left(x_{i}-\bar{x}\right)^{2}} \sqrt{\sum_{\mathrm{i}=1}^{\mathrm{n}}\left(y_{i}-\bar{y}\right)^{2}}},
$$

where $n$ is sample size, $x_{i}$ and $y_{i}$ are the individual sample points indexed with $i$, and $\bar{x}$ and $\bar{y}$ are the sample averages.

Table 1. All variables available in the database.

\begin{tabular}{clc}
\hline Abbreviation & \multicolumn{1}{c}{ Complete Name } & Unit \\
\hline$\% \mathrm{CaO}$ & Calcium Oxide Percentage & $\%$ \\
\hline$\% \mathrm{Fe}_{2} \mathrm{O}_{3}$ & Iron Oxide Percentage & $\%$ \\
\hline$\% \mathrm{MnO}$ & Manganese Dioxide Percentage & $\%$ \\
\hline$\% \mathrm{Na}_{2} \mathrm{O}$ & Sodium Oxide Percentage & $\%$ \\
\hline$\% \mathrm{P}_{2} \mathrm{O}_{5}$ & Phosphorus Pentoxide Percentage & $\%$ \\
\hline$\% \mathrm{SiO}_{2}$ & Silicon Oxide Percentage & $\%$ \\
\hline$\% \mathrm{TiO}_{2}$ & Titanium Dioxide Percentage & $\%$ \\
\hline$\% \mathrm{~V}_{2} \mathrm{O}_{5}$ & Vanadium Pentoxide Percentage & $\%$ \\
\hline$\% \mathrm{ZnO}$ & Zinc Oxide Percentage & $\%$ \\
\hline$<325 \mathrm{~m}$ & $<325$ Mesh & $\%$ \\
\hline$>100 \mathrm{~m}$ & $>100$ Mesh & $\%$ \\
\hline$>200 \mathrm{~m}$ & $>200$ Mesh & $\%$ \\
\hline
\end{tabular}


Table 1. Cont.

\begin{tabular}{|c|c|c|}
\hline Abbreviation & Complete Name & Unit \\
\hline CR & Friction Index & $\%$ \\
\hline CRF & Thin Crust & $\%$ \\
\hline $\mathrm{DA}$ & Apparent Density & $\mathrm{g} / \mathrm{cm}^{3}$ \\
\hline LOI1 & Loss on ignition $\left(300-1000{ }^{\circ} \mathrm{C}\right)$ & $\%$ \\
\hline LOI2 & Loss on ignition $\left(110-1000^{\circ} \mathrm{C}\right)$ & $\%$ \\
\hline LOI3 & Loss on ignition $\left(110-300^{\circ} \mathrm{C}\right)$ & $\%$ \\
\hline SE & Specific Surface & $\mathrm{m}^{2} / \mathrm{g}$ \\
\hline$\%$ FE & Iron Content in Metal & ppm \\
\hline$\% \mathrm{Ga}$ & Gallium Content & $\%$ \\
\hline$\% \mathrm{Mn}$ & Manganese Content & $\%$ \\
\hline$\% \mathrm{Na}$ & Sodium Content in Metal & $\%$ \\
\hline$\% \mathrm{Ni}$ & Nickel Content & $\%$ \\
\hline$\% \mathrm{P}$ & Metal Phosphorus Content & ppm \\
\hline$\% \mathrm{SI}$ & Silicon Content in Metal & ppm \\
\hline$\%$ TBase & Percentage of Time on Base Feed & $\%$ \\
\hline \%TChk & Check Feed Time Percentage & $\%$ \\
\hline \%TInic & Percentage of Initial Feeding Time & $\%$ \\
\hline \%TOthers & Percentage of Time Other Feeding Modes & $\%$ \\
\hline$\% \mathrm{TOV}$ & Percentage of Feeding Over Time & $\%$ \\
\hline$\%$ TUN & Percentage of Feeding Time Under & $\%$ \\
\hline$\% V_{-}$ & Vanadium Content & $\%$ \\
\hline $\mathrm{A} \% 1$ & Feeding $\left(\mathrm{Al}_{2} \mathrm{O}_{3}\right)$ & $\%$ \\
\hline ALF & Aluminum Fluoride (\% in Bath) & $\%$ \\
\hline ALF3A & Amount of AlF3 Added & $\mathrm{kg} / \mathrm{Misc}$ \\
\hline ALF3AB & AlF3-Base Addition-Total & $\mathrm{kg} /$ Misc \\
\hline ALF3ABF & AlF3-Base Addition-ABF & $\mathrm{kg} / \mathrm{t} \mathrm{Al}$ \\
\hline ALF3ABFC & AlF3-Base Addition-Factor C & $\mathrm{kg} / \mathrm{t} \mathrm{Al}$ \\
\hline ALF3ABN & AlF3-Base Addition- $\mathrm{Na}_{2} \mathrm{O}$ & $\mathrm{kg} / \mathrm{t} \mathrm{Al}$ \\
\hline ALF3ABT & AlF3-Base Addition-Total & $\mathrm{kg} / \mathrm{Misc}$ \\
\hline ALF3ABV & AlF3-Base Addition-Life & $\mathrm{kg} / \mathrm{Misc}$ \\
\hline ALF3Ac & Amount of AlF3 Added-Correction & $\mathrm{kg} / \mathrm{Misc}$ \\
\hline ALF3AE & ALF3A-Extra Addition & $\mathrm{kg} / \mathrm{Misc}$ \\
\hline ALF3Ah & Amount of AlF3 Added-Historic & $\mathrm{kg} / \mathrm{Misc}$ \\
\hline ALF3Am & Amount of AlF3 Added-Maintenance & $\mathrm{kg} / \mathrm{Misc}$ \\
\hline ALF3AR & AlF3 Deviation Reference & $\mathrm{kg} / \mathrm{Misc}$ \\
\hline ALF3ARB & ALF3A-[Real-Base] & $\mathrm{kg} / \mathrm{Misc}$ \\
\hline ALF3AS & AlF3-Hopper Balance Correction & $\mathrm{kg} / \mathrm{Misc}$ \\
\hline ALF3At & Amount of AlF3 Added-Trend & $\mathrm{kg} / \mathrm{Misc}$ \\
\hline ALF3ATS & Hopper Balance & $\mathrm{kg} / \mathrm{Misc}$ \\
\hline ALF3ATSAc & Accumulated Hopper Balance & $\mathrm{kg} / \mathrm{Misc}$ \\
\hline
\end{tabular}


Table 1. Cont.

\begin{tabular}{|c|c|c|}
\hline Abbreviation & Complete Name & Unit \\
\hline ALF3CA & AlF3-\% AlF3 Correction & $\mathrm{kg} / \mathrm{Misc}$ \\
\hline ALF3CM & AlF3 Quantity-Manual Correction & $\mathrm{kg} / \mathrm{Misc}$ \\
\hline ALF3CT & AlF3-Temperature Correction & $\mathrm{kg} / \mathrm{Misc}$ \\
\hline ALF3DA & AlF3 Added-Cumulative Deviation & $\mathrm{kg}$ \\
\hline ALF3DALI & AlF3-Accumulated Deviation-Lower Limit & $\mathrm{kg}$ \\
\hline ALF3DALS & AlF3-Accumulated Deviation-Upper Limit & $\mathrm{kg}$ \\
\hline ALF3LC & AlF3-Limit Check Correction & $\mathrm{kg} / \mathrm{Misc}$ \\
\hline ALFca & Aluminum Fluoride for CA & $\%$ \\
\hline ALFcalc & Calculated Aluminum Fluoride & $\%$ \\
\hline ALM & Feeder & $\mathrm{Kg}$ \\
\hline CAF & Calcium Fluoride (\% in Bath) & $\%$ \\
\hline CAF2A & Amount of $\mathrm{CaF}_{2}$ Added & $\mathrm{kg}$ \\
\hline CAF2CM & $\mathrm{CaF}_{2}$ Quantity-Manual Correction & $\mathrm{kg}$ \\
\hline CAN & Anode Coverage & $\mathrm{cm}$ \\
\hline CE & Specific Energy Consumption & $\mathrm{kWh} / \mathrm{kg} \mathrm{Al}$ \\
\hline CoLiq & Liquid Column & $\mathrm{cm}$ \\
\hline CQB-Efetiv & Chemical Bath Control-Effectiveness & $\%$ \\
\hline DeltaR & Resistance Delta & $\mathrm{uOhm}$ \\
\hline DeltaT & Super Heat & ${ }^{\circ} \mathrm{C}$ \\
\hline DeltaT1 & Super Heat & ${ }^{\circ} \mathrm{C}$ \\
\hline DeltaTM & Super Heat Measured & ${ }^{\circ} \mathrm{C}$ \\
\hline DeltRCI & DeltaR-Instability Calculation & $\mathrm{uOhm}$ \\
\hline DesAnodCAR & Anode Descent in CAR & un \\
\hline DesAutAnod & Automatic Anode Descent & un \\
\hline DifNME & Metal Level (Real-Set) & $\mathrm{cm}$ \\
\hline DifRMR & Rreal-Rset & $\mathrm{uOhm}$ \\
\hline DifRSO & Rtarget-Rset & $\mathrm{uOhm}$ \\
\hline DRPTro & Post-Trade Resistance Delta & $\mathrm{uOhm}$ \\
\hline EaEnergL & Anode Effect (AE)-Net Energy & Kwh/EA \\
\hline EAN & Unscheduled Anode Effect & $\mathrm{EA} / \mathrm{d}$ \\
\hline EAP & Scheduled Anode Effect & $\mathrm{ea} / \mathrm{d}$ \\
\hline EaDurPol & AE-Polarization Duration & $\mathrm{seg} / \mathrm{Ea}$ \\
\hline EaDurPolTot & AE-Total Duration of Polarization & seg/F/Day \\
\hline EaVBruta & AE-Gross Voltage & V/Ea \\
\hline EaVLiq & AE-Liquid Voltage & $\mathrm{V} / \mathrm{Ea}$ \\
\hline EaVMax & AE-Maximum Voltage & $\mathrm{V}$ \\
\hline EaVPol & AE-Voltage Polarization & $\mathrm{V} / \mathrm{Ea}$ \\
\hline $\mathrm{ECO}$ & Current Efficiency & $\%$ \\
\hline FAB & AlF3 Base Addition & $\mathrm{kg} / \mathrm{Misc}$ \\
\hline
\end{tabular}


Table 1. Cont.

\begin{tabular}{|c|c|c|}
\hline Abbreviation & Complete Name & Unit \\
\hline FARB & Addition (Real + Extra - Base) & $\mathrm{kg} / \mathrm{Misc}$ \\
\hline IMx & Current Intensity & $\mathrm{kA}$ \\
\hline IncCTAlim & Increment-CTFeed & $\mathrm{uOhm}$ \\
\hline IncCTOsc & Increment-CTOsc & $\mathrm{uOhm}$ \\
\hline IncOp & Increment-Operation & $\mathrm{uOhm}$ \\
\hline IncOs & Increment-Oscillation & $\mathrm{uOhm}$ \\
\hline IncTm & Increment-Temperature & $\mathrm{uOhm}$ \\
\hline IncTr & Increment-Anode Exchange & $\mathrm{uOhm}$ \\
\hline $\mathrm{Na}$ & Sodium Content in Metal (PPM) & ppm \\
\hline NA2CO3A & Added Amount of $\mathrm{Na}_{2} \mathrm{CO}_{3}$ & $\mathrm{~kg}$ \\
\hline NA2CO3CM & $\mathrm{Na}_{2} \mathrm{CO}_{3}$ Quantity-Manual Correction & $\mathrm{kg}$ \\
\hline NBA & Bath Level & $\mathrm{cm}$ \\
\hline NBAA & Bath Addition & $\mathrm{Kg}$ \\
\hline NBAc & Bath Control & $\mathrm{Kg}$ \\
\hline NBAR & Bath Removal & $\mathrm{Kg}$ \\
\hline NCicSEA & SEA Cycle Number & Ciclos/SEA \\
\hline NEA & Total Anode Effect & ea/d \\
\hline NEARecorr & Total Recurrent Anode Effect & $\mathrm{EA} / \mathrm{d}$ \\
\hline NME & Metal Level & $\mathrm{cm}$ \\
\hline NOV & Number of Overs & un \\
\hline NSA & Number of Feed Shots & un \\
\hline NTR & Number of Tracks & - \\
\hline NumOverUnder & Number of Overs Followed by Unders & un \\
\hline PAN & Anodic Loss & $\mathrm{uOhm}$ \\
\hline PCA & Cathodic Loss & $\mathrm{mV}$ \\
\hline $\mathrm{PCO}$ & Cathodic Loss (uOhms) & $\mathrm{mOhm}$ \\
\hline PHV & Loss Rod Beam & $\mathrm{uOhm}$ \\
\hline PreEA & Anode Pre-Effect & $\mathrm{ea} / \mathrm{d}$ \\
\hline PrvEA & Anode Effect Prediction & ea/d \\
\hline PUR & Metal Purity $(\% \mathrm{Al})$ & $\%$ \\
\hline QALr & Feed Quantity (Real) & $\mathrm{kg}$ \\
\hline QALt & Feed Quantity (Theoretical) & $\mathrm{kg}$ \\
\hline QME & Amount of Flushed Metal (Real) & ton \\
\hline RMR & Real Resistance & $\mathrm{uOhm}$ \\
\hline RS & Resistance Setpoint & $\mathrm{uOhm}$ \\
\hline RSO & Target Resistance & $\mathrm{uOhm}$ \\
\hline SetNBA & Bath Level Setpoint & $\mathrm{cm}$ \\
\hline SetNME & Metal Level Setpoint & $\mathrm{cm}$ \\
\hline SILO & Alf3 Silo Filling Control & - \\
\hline SIM & Impossible Anode Effect Suppression & $\%$ \\
\hline
\end{tabular}


Table 1. Cont.

\begin{tabular}{|c|c|c|}
\hline Abbreviation & Complete Name & Unit \\
\hline SIMTot & Impossible Total Anode Effect Suppression & $\%$ \\
\hline SPEA & Anode Pre-Suppression & $\mathrm{ea} / \mathrm{d}$ \\
\hline SPEAIM & Impossible Anode Pre-Effect Suppression & $\%$ \\
\hline SubAnodCAR & CAR Anode Rise & un \\
\hline SubAutAnod & Automatic Anode Rise & un \\
\hline SWF & Strong Oscillation & $\%$ \\
\hline SWT & Total Oscillation & $\%$ \\
\hline TAS & Suspended Feed Time & $\min$ \\
\hline TC1 & Check Time & $\min$ \\
\hline TEA & Anode Effect Time & $\min$ \\
\hline TMP & Bath Temperature & ${ }^{\circ} \mathrm{C}$ \\
\hline TMPcat & CA Bath Temperature & ${ }^{\circ} \mathrm{C}$ \\
\hline TMPLI & Bath Temperature-Lower Limit & ${ }^{\circ} \mathrm{C}$ \\
\hline TMPLiq & Liquid Temperature & ${ }^{\circ} \mathrm{C}$ \\
\hline TMPLS & Bath Temperature-Upper Limit & ${ }^{\circ} \mathrm{C}$ \\
\hline TMT & Track Time & $\min$ \\
\hline TOV & Over Time & $\min$ \\
\hline TUN & Under Time & $\min$ \\
\hline VIDA & Pot Life & days \\
\hline WF & Real Consumption of Oven & $\mathrm{kW}$ \\
\hline WFA & Oven Target Consumption & $\mathrm{kW}$ \\
\hline $\mathrm{AF}$ & Fresh Alum Silo Level & $\%$ \\
\hline $\mathrm{af} \% \mathrm{~F}$ & Adsorbed Fluoride (Fluorinated Alumina) & $\%$ \\
\hline af\%F(Cor) & Corrected plant fluoridation & $\%$ \\
\hline $\mathrm{af} \% \mathrm{Na} 2 \mathrm{O}$ & Sodium Oxide (Fluorinated Alumina) & $\%$ \\
\hline af $\%$ UM & Moisture (Fluorinated Alumina) & $\%$ \\
\hline Af $<325 \mathrm{~m}$ & $<325$ Mesh (Fluorinated Alumina) & $\%$ \\
\hline Af $<400 \mathrm{~m}$ & $<400$ Mesh (Fluorinated Alumina) & $\%$ \\
\hline Af $>100 \mathrm{~m}$ & >100 Mesh (Fluorinated Alumina) & $\%$ \\
\hline Af $>200 \mathrm{~m}$ & >200 Mesh (Fluorinated Alumina) & $\%$ \\
\hline afDA & Apparent Density (Fluorinated Alumina) & $\mathrm{g} / \mathrm{cm}^{3}$ \\
\hline afLOI1 & L.O.I. $\left(110-300{ }^{\circ} \mathrm{C} ; \mathrm{AF}\right)$ & $\%$ \\
\hline AluT & Transported Alumina & $\mathrm{T}$ \\
\hline Na2Odif & $\begin{array}{l}\text { Sodium Oxide (Fluorinated } \\
\text { Alumina-Virgin) }\end{array}$ & $\%$ \\
\hline SPVZ & Fresh Alumina Flow Setpoint & $\mathrm{T} / \mathrm{h}$ \\
\hline $\mathrm{VZ}$ & Fresh Alumina Flow & $\mathrm{T} / \mathrm{h}$ \\
\hline af\%UMx & Moisture (Fluorinated Alumina) & $\%$ \\
\hline ALF LI & Lower Limit ALF & $\%$ \\
\hline ALF LS & ALF Upper Limit & $\%$ \\
\hline
\end{tabular}


Table 1. Cont.

\begin{tabular}{clc}
\hline Abbreviation & \multicolumn{1}{c}{ Complete Name } & Unit \\
\hline IA & Target Current & $\mathrm{kA}$ \\
\hline IM & Current Intensity & $\mathrm{kA}$ \\
\hline IMBB & Booster Current Intensity & $\mathrm{kA}$ \\
\hline IMC & Current Intensity (Pot) & $\mathrm{kA}$ \\
\hline IMRB & Current Intensity & $\mathrm{kA}$ \\
\hline VL & Line Voltage & $\mathrm{V}$ \\
\hline WL & Actual Line Consumption & $\mathrm{MW}$ \\
\hline ECp & Predicted Current Efficiency & $\%$ \\
\hline ECr & Real Current Efficiency & $\%$ \\
\hline PRODReal & Real Production & $\mathrm{t}$ \\
\hline
\end{tabular}

Table 2 lists the most important inputs associated with output variables selected to create the estimation models. Firstly, the inputs have been determined after a Pearson correlation study (Equation (2)). After that, process engineers validated the feature selection to the model. It is important to note that all input variables are delayed by one step, because neural models emulate a first order dynamic system with delayed inputs to estimate the current output. The final selected dataset had about 1,728,000 samples and eleven inputs and three outputs.

Table 2. Variables used for the modeling.

\begin{tabular}{|c|c|c|c|c|c|c|c|c|}
\hline ID & Type & Variable & Abbreviation & Unit & Delay & $\begin{array}{c}\text { R } \\
\text { w/TMP }\end{array}$ & R w/ALF & $\frac{\mathrm{R}}{\mathrm{w} / \mathrm{NME}}$ \\
\hline 1 & \multirow{6}{*}{ Input } & Gross Voltage & VMR-1 & $\mathrm{V}$ & \multirow{7}{*}{ 1-step } & -0.49 & 0.43 & 0.30 \\
\hline 3 & & Bath Level & NBA-1 & $\mathrm{cm}$ & & 0.58 & -0.41 & -0.69 \\
\hline 4 & & $\begin{array}{l}\text { Calcium Fluoride } \\
\text { (\% in the Bath) }\end{array}$ & CAF-1 & $\%$ & & -0.53 & -0.49 & 0.37 \\
\hline 7 & & Amount of AlF3 Added & ALF3A-1 & $\mathrm{kg} / \mathrm{misc}$ & & 0.40 & -0.46 & -0.30 \\
\hline 8 & & Amount Fed (Real) & QALR-1 & $\mathrm{kg}$ & & -0.35 & 0.32 & 0.52 \\
\hline 9 & & Temperature & TMP-1 & ${ }^{\circ} \mathrm{C}$ & & 0.88 & -0.79 & 0.32 \\
\hline 10 & \multirow{2}{*}{ Output } & $\begin{array}{l}\text { Aluminum Fluoride } \\
\text { (\% in the Bath) }\end{array}$ & ALF-1 & $\%$ & & -0.78 & 0.94 & 0.25 \\
\hline 14 & & Metal Level & NME & $\mathrm{cm}$ & - & - & - & - \\
\hline
\end{tabular}

Some variables, such as temperature, percentage of fluoride, and metal level, are collected manually by physical sensors or through laboratory analysis, generating different sampling frequencies. Other variables, for instance real resistance and raw voltage, are collected online via sensors without human interference. Most of the variables are sampled on a daily basis; however, variables that are collected manually have other sampling frequencies. This fact causes null data to be present between measurements when combining variables from different samplings. Missing data were imputed by calculating a linear interpolation between the previous and subsequent measurements, according to the variable sampling. According to process engineers, linear interpolation fits well, because the chemical process is slow and it has been validated before. Figure 6 shows an imputation example for bath temperature. The soft sensors described in this work have the advantage of being capable of estimating missing data after they have been properly trained. 

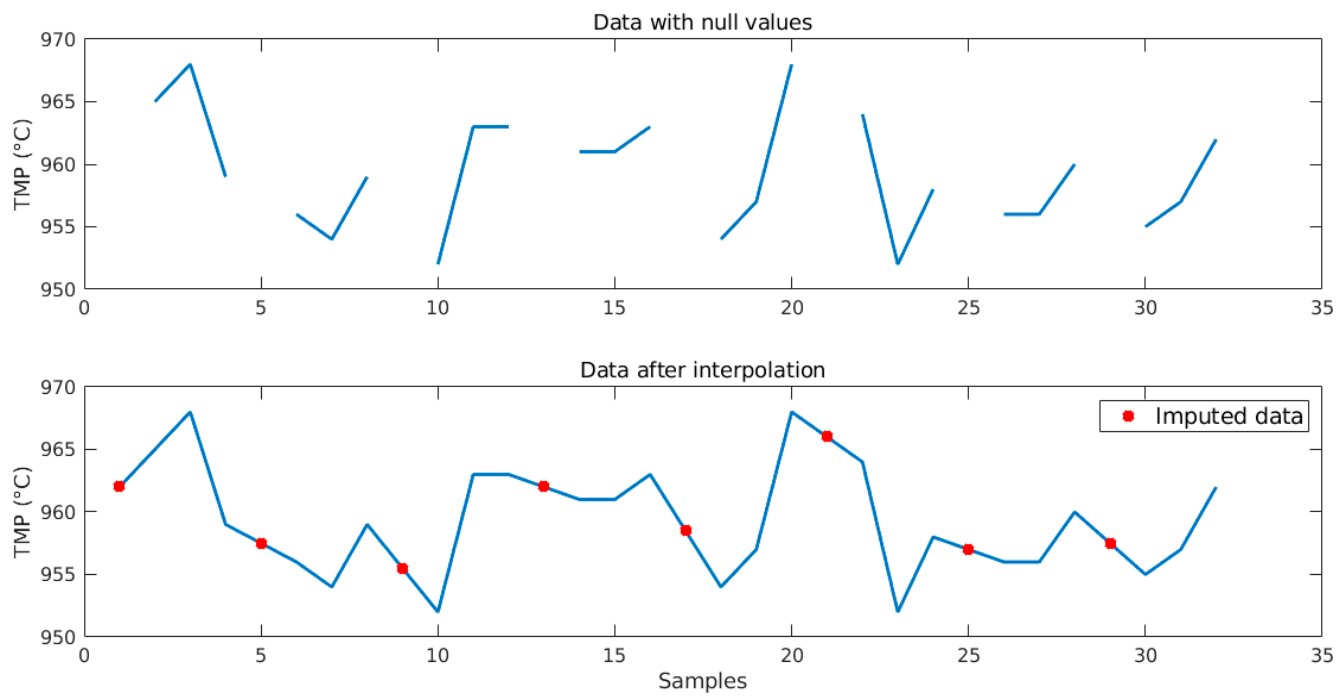

Figure 6. Example of data imputation for bath temperature.

Process engineers also agree there are three different types of behaviors produced by pots according to their lifespan: a lifespan of 1-100 days is considered a "starting point"; 101-1200 days as a "stationary regime"; and 1201-1500 days as the "shutdown point". This lifespan division is the second method used to cluster the entire dataset (the first is clustering by section, explained before). These ranges may vary according to the pot, but they are the same on average. Figure 7 summarizes behaviors and the amount of data for each lifespan division.

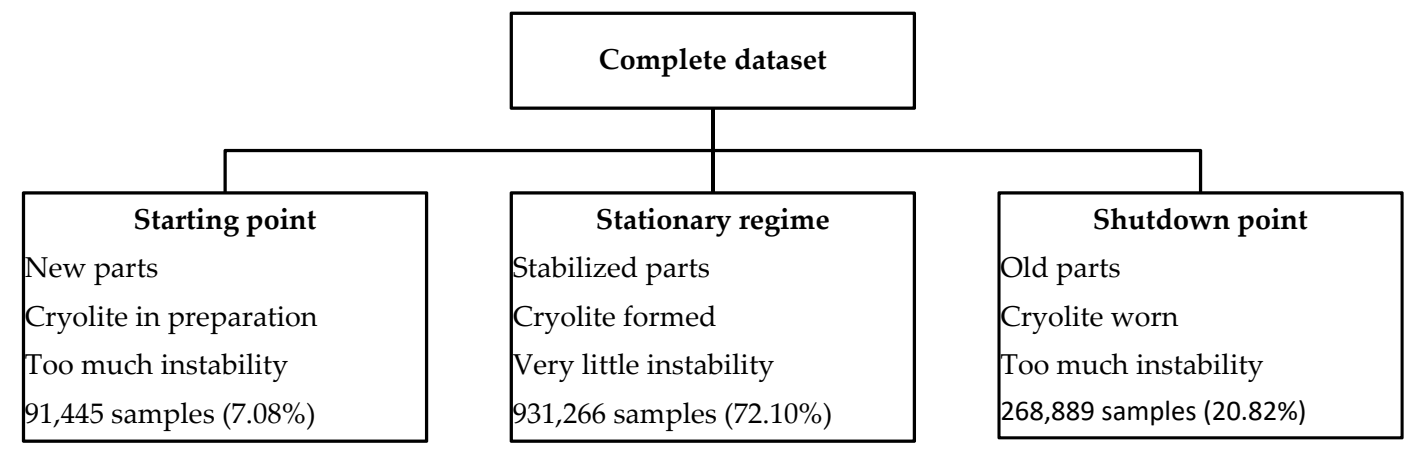

Figure 7. Description of each lifespan division.

The different behaviors also may be verified when the dataset of each group is statistically analyzed. Figure 8 shows histograms of each input variable for each group. The ALF3A variable has zero values at the starting point, because it is not observed in this phase, so this variable may be discarded when models for this phase are created. The PNA2O variable at the starting point has a larger number of samples less than 0.4 ; in the stationary regime and shutdown point, the higher concentration of samples is more than 0.4 . The behavior of input variables between stationary regime and shutdown point is similar. 

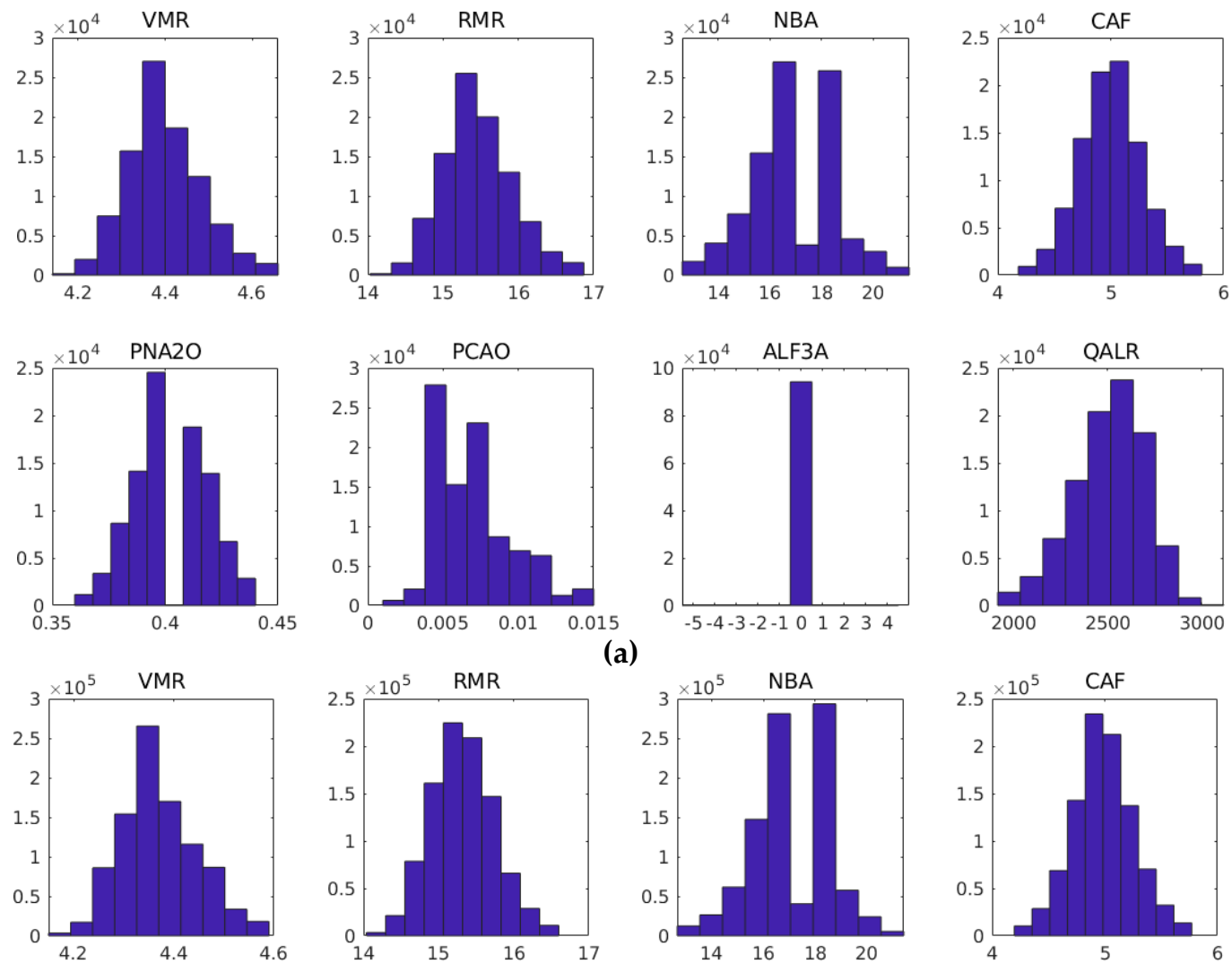

(a)
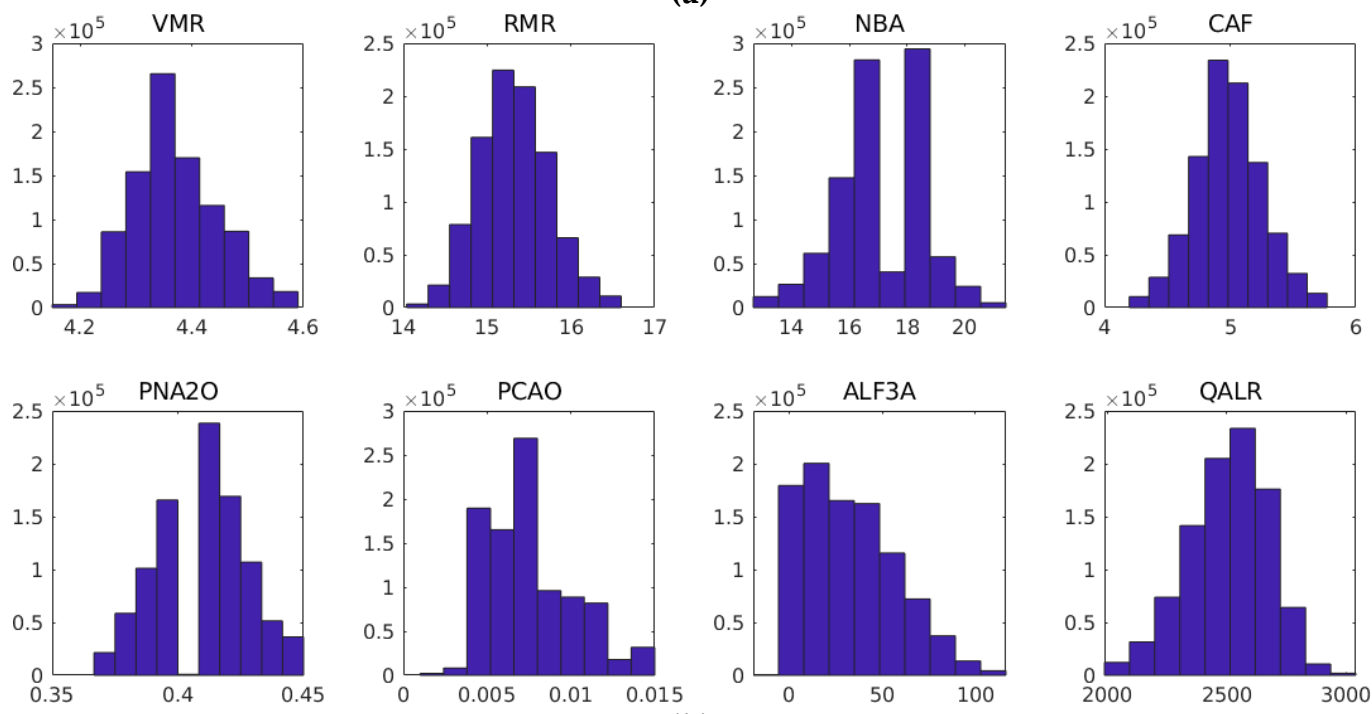

(b)
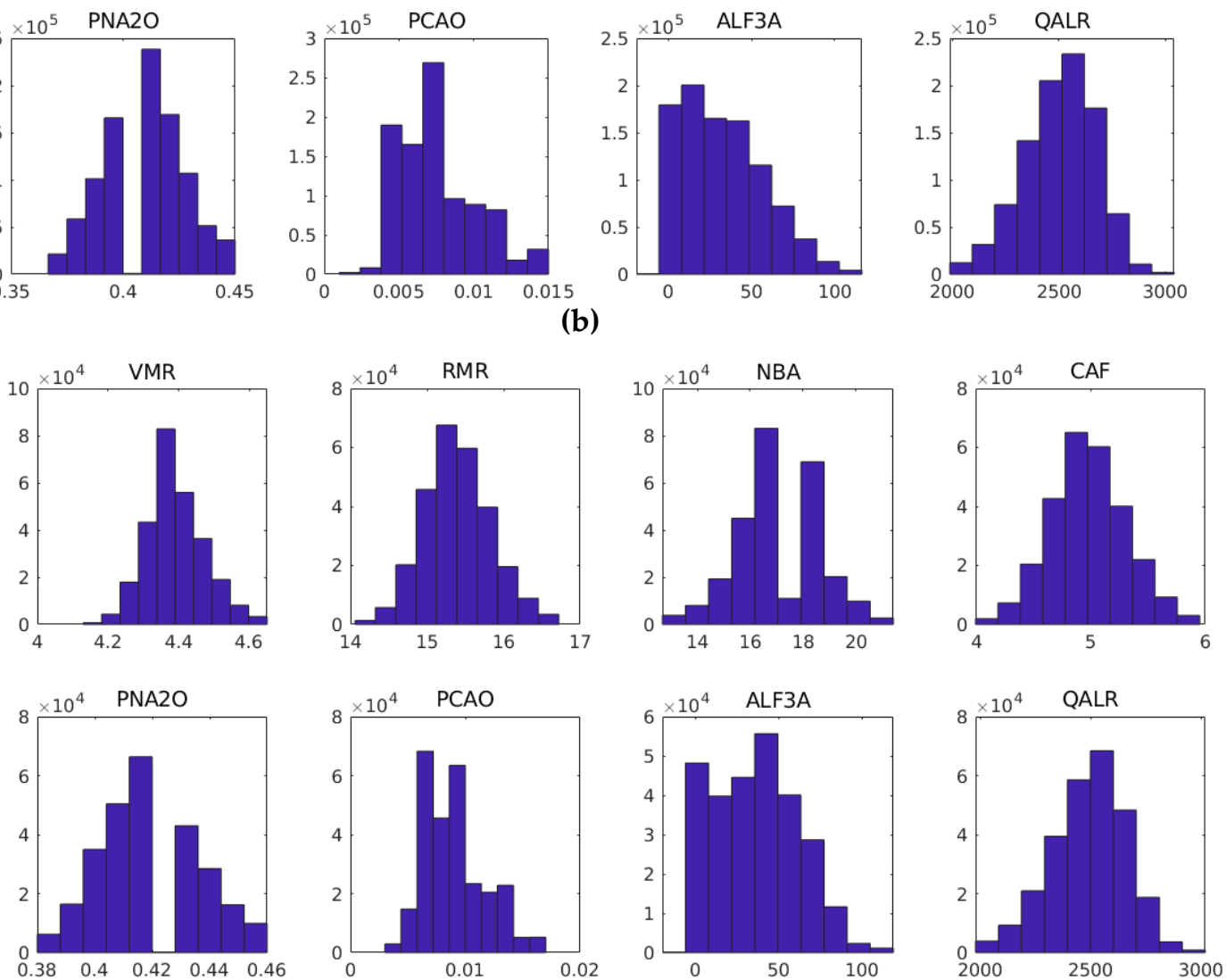

(c)

Figure 8. Input variables histogram: (a) starting point; (b) stationary regime; and (c) shutdown regime. 
Analyzing the output variables histogram for each behavior (Figure 9), it is possible to observe that the TMP variable at the starting and shutdown points had a range of values greater than the stationary regime, ratifying the instability thesis. Another behavior verified was about the NME variable: at the starting point it had a large accumulation of samples at 24 , but in the stationary and shutdown phases the accumulation was 25. The ALF variable at the starting point had a larger sample concentration less than 10; in the other two phases the concentration was greater than 10.
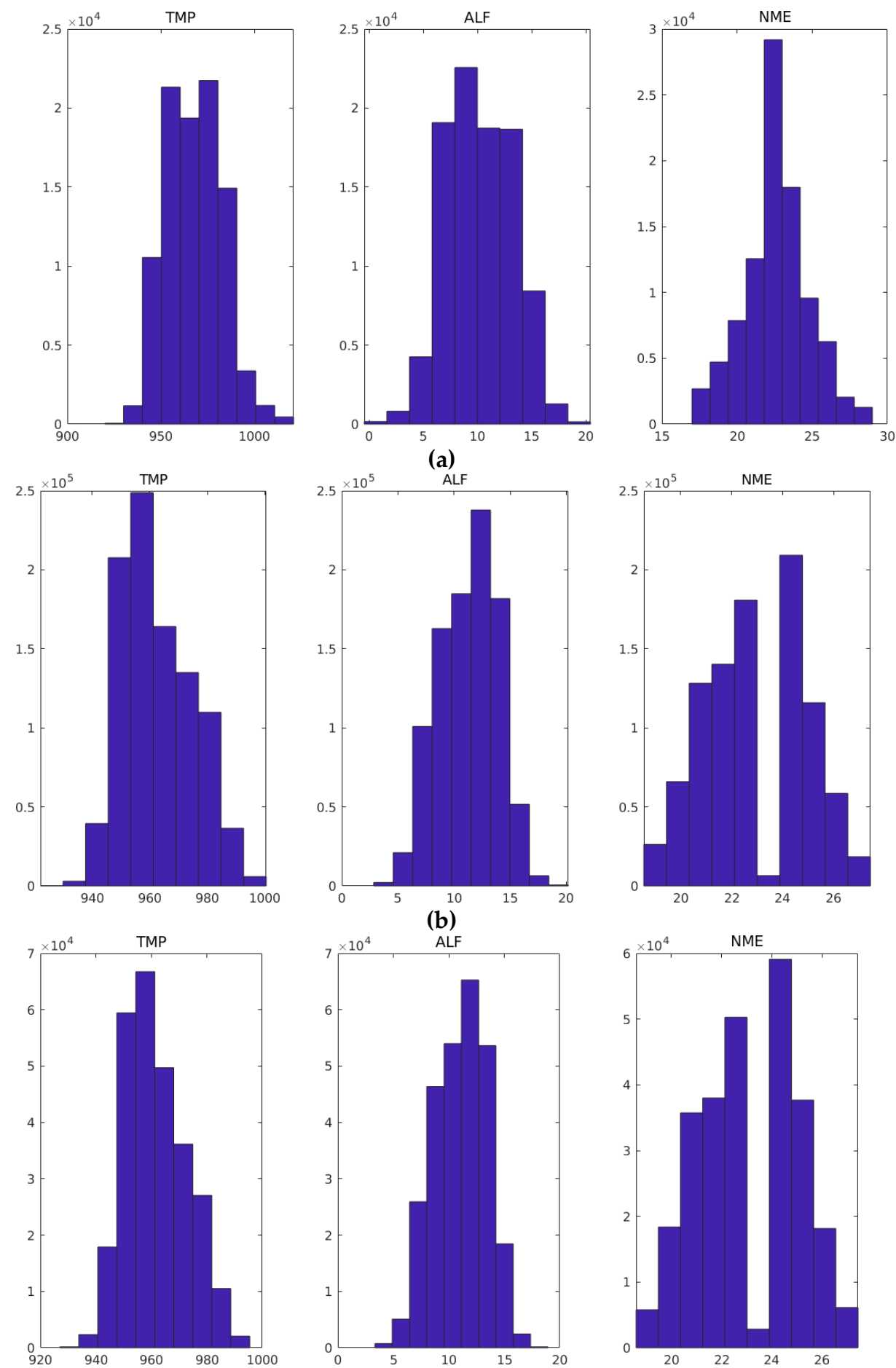

(c)

Figure 9. Output variables histogram: (a) starting point; (b) stationary regime; and (c) shutdown point. 
Besides histograms, the difference in TMP variation can be observed in the three phases by Figure 10. In starting point, the mean is equals $970.5^{\circ} \mathrm{C}$, because the pot must be reheated; in stationary regime, the mean decreases to $963.7^{\circ} \mathrm{C}$, the standard mean of the plant; and in shutdown point, it also decreases to $958.8^{\circ} \mathrm{C}$, since the pot is being cooled to turn off. TMP was chosen to perform this analysis, because it is one of the most monitored process variables.
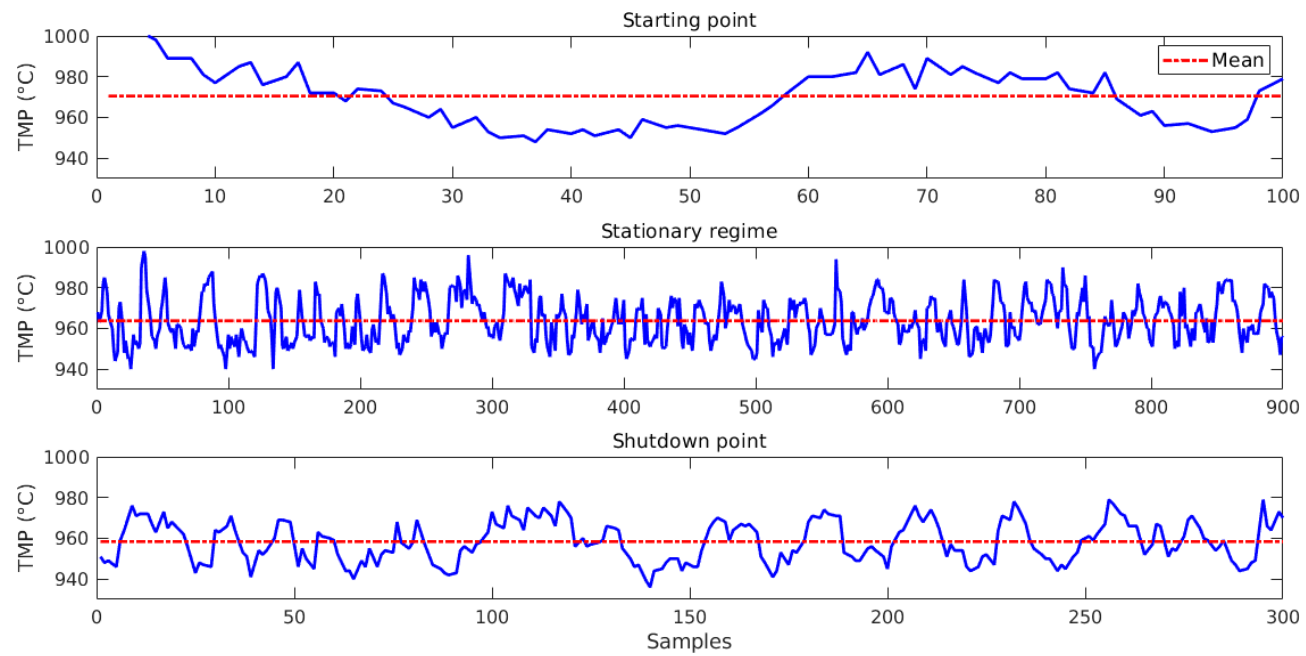

Figure 10. Bath temperature variation of the pot 5 .

The following subsection shows the steps performed in the original database in order to generate the resulting models.

\subsection{Strategy for Modeling}

Data clustered by each section and by each lifespan division were used to build models to estimate TMP, ALF, and NME using the ANN technique. It is important to know that each ANN model has only one of three outputs and two different training algorithms were used to create them: Levenberg-Marquardt (LM) and back propagation (BP). Besides, three strategies were used for each technique:

1. Consider $70 \%$ of the data from each cluster to train, $15 \%$ to validate, and $15 \%$ to test the models.

2. Consider data from all pots of one entire section to train the models, except for one pot of the respective section to test the model. This was applied to section clustering and lifespan division.

3. Dataset standardization was done using the z-score method.

The $\mathrm{z}$-score generates a standardized dataset with average equal to 0 and standard deviation equal to 1 and it is expressed by:

$$
z=\frac{x-\mu}{\sigma}
$$

where $x$ is the value to be standardized, $\mu$ is the average of the variable, and $\sigma$ is the standard deviation of the variable.

Table 3 shows the division of the complete dataset for the modeling process: for each lifespan division or all datasets and two different learning algorithms. Moreover, three strategies were used for each technique, 32 different pot sections, whole dataset, and three outputs, resulting in 594 different models, initially. 
Table 3. Complete modeling process.

\begin{tabular}{ccc}
\hline Lifespan Division & Training Algorithm & Number of Models \\
\hline \multirow{2}{*}{ Starting point } & ANN-LM & 32 sections $\times 3$ outputs $=96$ \\
& & All dataset $\times 3$ outputs $=3$ \\
& ANN-BP & 32 sections $\times 3$ outputs $=96$ \\
Stationary regime & All dataset $\times 3$ outputs $=3$ \\
& ANN-LM & 32 sections $\times 3$ outputs $=96$ \\
& ANN-BP & All dataset $\times 3$ outputs $=3$ \\
Shutdown point & All dataset $\times 3$ outputs $=3$ \\
& ANN-LM & 32 sections $\times 3$ outputs $=96$ \\
& & All dataset $\times 3$ outputs $=3$ \\
& ANN-BP & 32 sections $\times 3$ outputs $=96$ \\
& & All dataset $\times 3$ outputs $=3$ \\
& TOTAL & 576 models (clustered data) \\
& & 18 models (all dataset) \\
& & 594 models \\
\hline
\end{tabular}

Each model was trained ten times, because the initial weights of the neural network and the division of training and validation data are random, according to a Gaussian probability density function. In total, 5760 neural networks were created considering clustered data, whereas 2880 models use the LM algorithm and 2880 use the BP algorithm. The pseudocode (Algorithm 1) summarizes the entire modeling process.

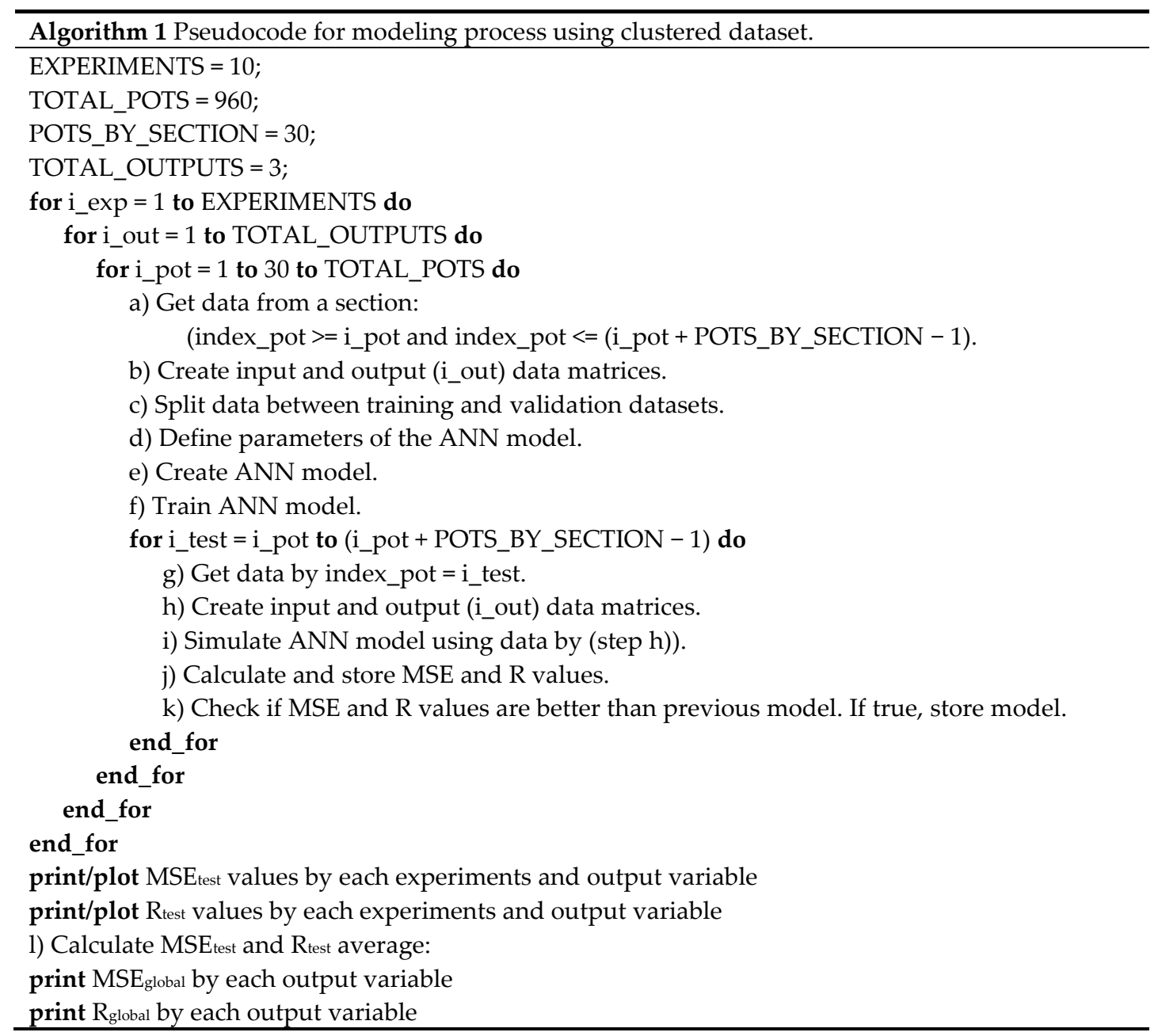


The mean squared error (MSE) and the R between target and estimated values were considered as quality metrics of the models. MSE is defined as:

$$
M S E=\frac{1}{n} \sum_{\mathrm{i}=1}^{\mathrm{n}}\left(y_{i}-\hat{y}_{i}\right)^{2},
$$

where $n$ is the number of samples, and $y_{i}$ and $\hat{y}_{i}$ are the target and estimated values by the model, respectively.

\subsection{Parameter Learning for ANN Models}

It is important to mention that there were empirical attempts to define the number of neurons in the hidden layer and transfer functions in the hidden and output layers. Empirical attempts considering $2,4,8,16,32,64$, and 128 neurons in the hidden layer were done and alternating the transfer function resulted in a small variation in training, validating, and testing MSE of $0.5 \%$. Therefore, it was decided to generate simpler models according to the parameters explained in Table 4.

Table 4. Artificial neural network (ANN) model details.

\begin{tabular}{lcl}
\hline \multicolumn{1}{c}{ Parameter } & Value & \multicolumn{1}{c}{ Justification } \\
\hline $\begin{array}{l}\text { Number of hidden layers } \\
\begin{array}{l}\text { Number of neurons in the hidden layer } \\
\text { Transfer function in the hidden layer } \\
\text { Transfer function in the output layer }\end{array}\end{array}$ & $\begin{array}{c}\text { Symmetric Sigmoid } \\
\text { Linear }\end{array}$ & Empirical attempts. \\
\hline & LM & $\begin{array}{l}\text { To build models faster, because this } \\
\text { algorithm considers an approximation of } \\
\text { Newton's method, which uses an array of } \\
\text { second-order derivatives and a first-order } \\
\text { derivative matrix (Jacobian matrix). On the } \\
\text { other hand, it uses more memory to } \\
\text { calculate optimal weights [76,77]. } \\
\text { To create models based on the most } \\
\text { traditional learning algorithm: descendent } \\
\text { gradient. It is slower than LM, but it uses } \\
\text { less memory [78,79]. }\end{array}$ \\
\hline
\end{tabular}

It is important to mention that the models were generated using MATLAB ${ }^{\circledR}$ version R2018a (The MathWorks Inc., Natick, MA, USA) on a computer equipped with a processor by Intel ${ }^{\circledR}$ Core $^{\mathrm{TM}}$ i7-3537U, CPU 2.00 GHz, 8 GB RAM, SSD (Solid State Disk).

\section{Results and Discussion}

After running the experiments, this section shows and discusses the results. Figure 11 shows the time spent in each set of experiments by lifespan division and the training algorithm. Once there were 32 different sections, three different outputs and ten experiments were done, so each point represents the training of 960 different models. All experiments consumed over two and a half hours in total, where the LM algorithm was almost twice as fast as the BP.

Figure 12 exemplifies the evolution of training, validating and testing of neural networks creation process for TMP output, considering starting point data. It is possible to verify LM converges faster and it is more accurate than BP. This same behavior was identified for the other outputs and lifespan divisions. 


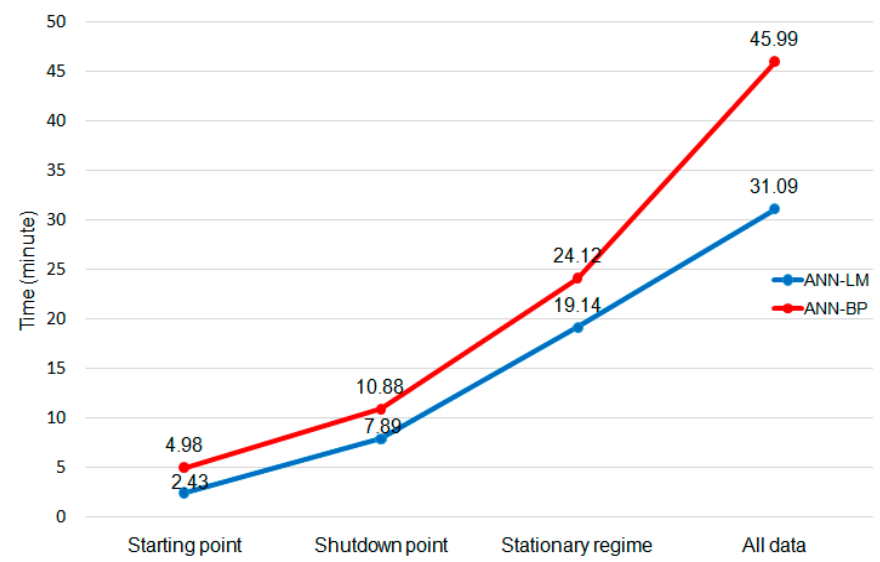

Figure 11. Time spent on ANN- Levenberg-Marquardt (LM) and ANN-back propagation (BP) experiments.

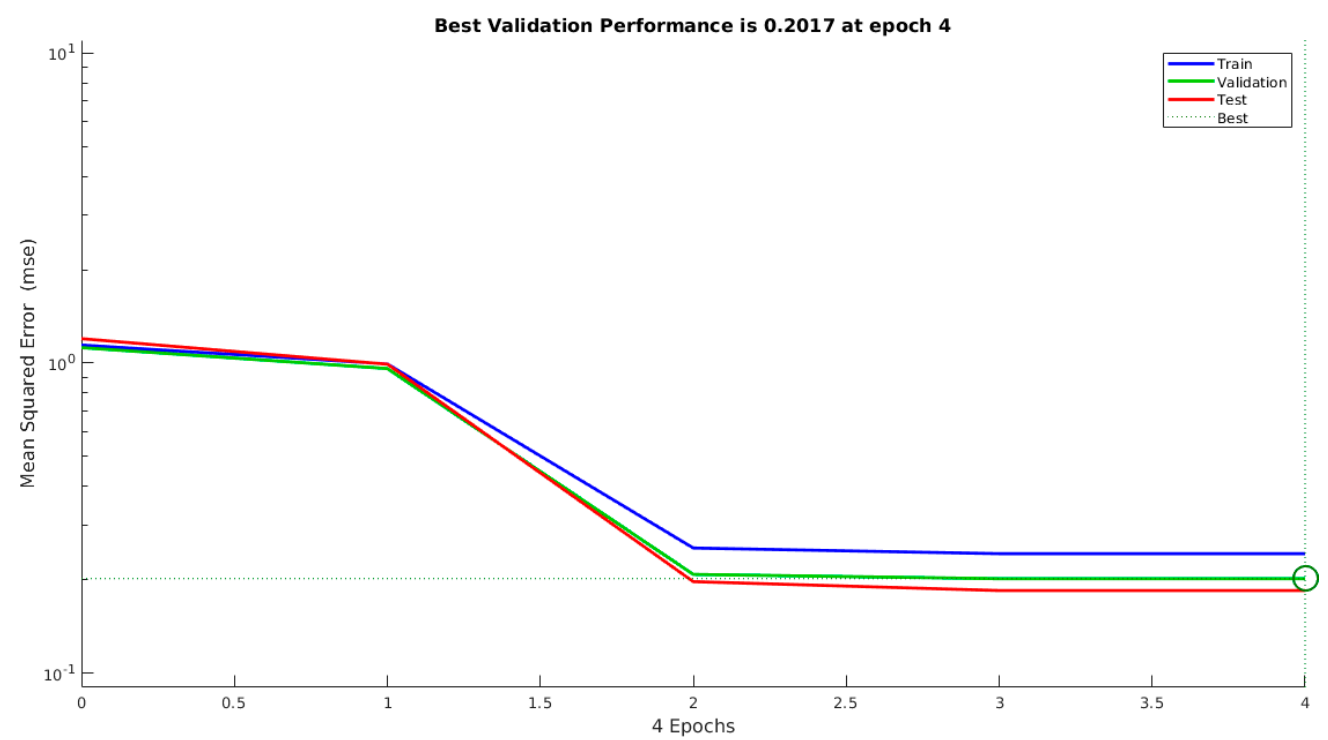

(a)

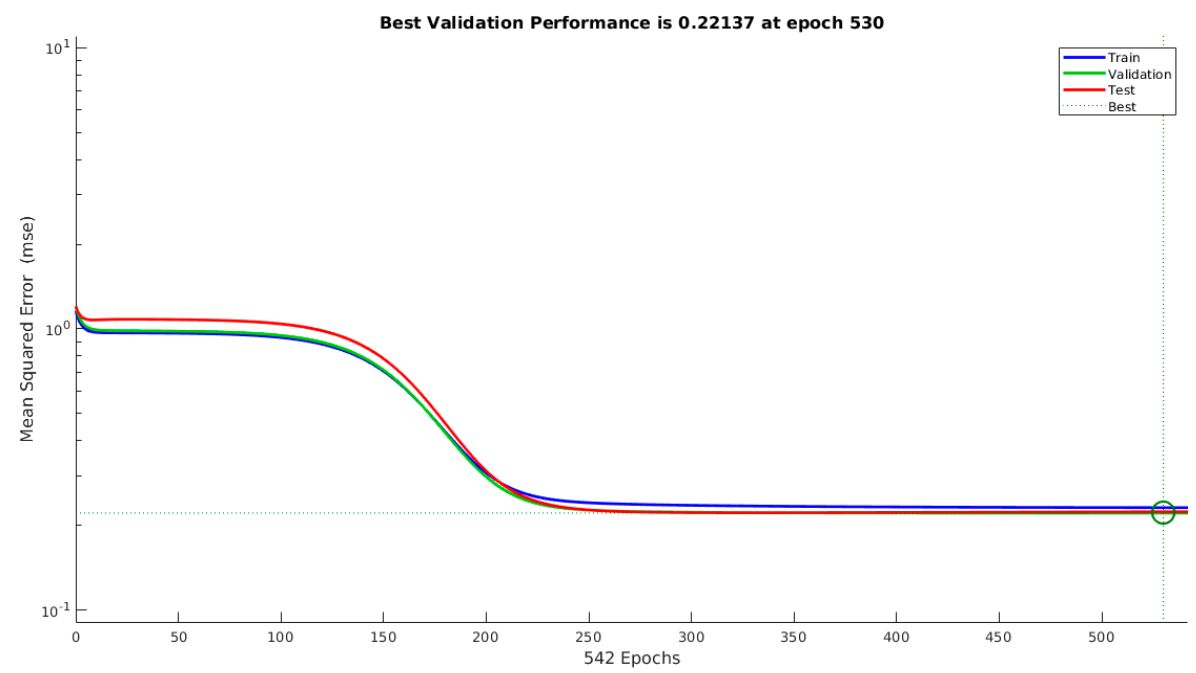

(b)

Figure 12. Examples of the evolution of training, validating and testing of neural networks creation process for TMP output: (a) LM algorithm; and (b) BP algorithm. 
Since the reduction pot always operates with the closed loop control, the available data are closed loop. In other words, the estimation of the variables made by the soft sensors is in a closed loop. Thus, the estimates obtained show bias deviations and inherent error in the frequency domain [72-76]. Since the reduction pot cannot operate in an open loop, these errors will be inherent in the estimates obtained, but are sufficiently useful for control $[73,76]$. Therefore, it is possible that data are affected by the change of the controller transfer function.

Figure 13 shows MSE and R values for 2880 models considering all pots in starting, stationary and shutdown phases, ANN-LM, the three output variables, and normalized data. Most models present low MSE values and high $\mathrm{R}$ values (the blue line is the average). Therefore, the contribution is to prove that the modeling strategy described worked properly.
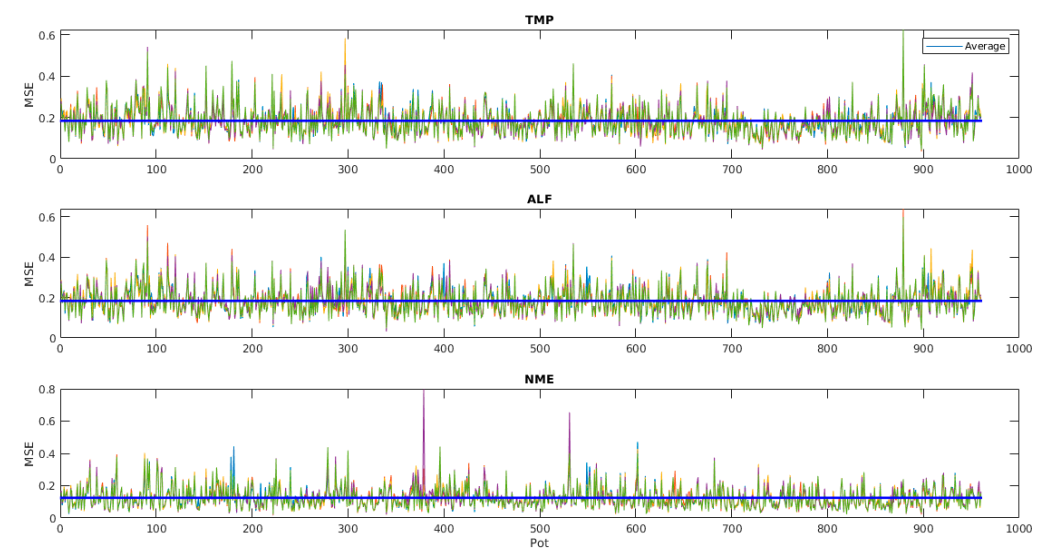

(a)

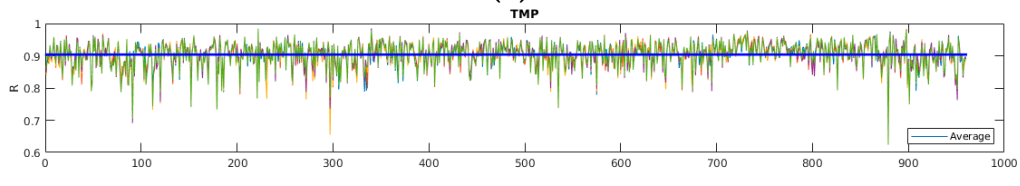

ALF
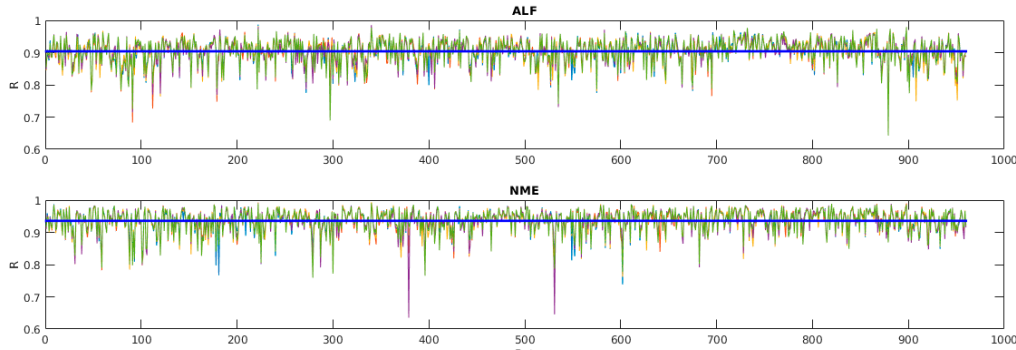

(b)
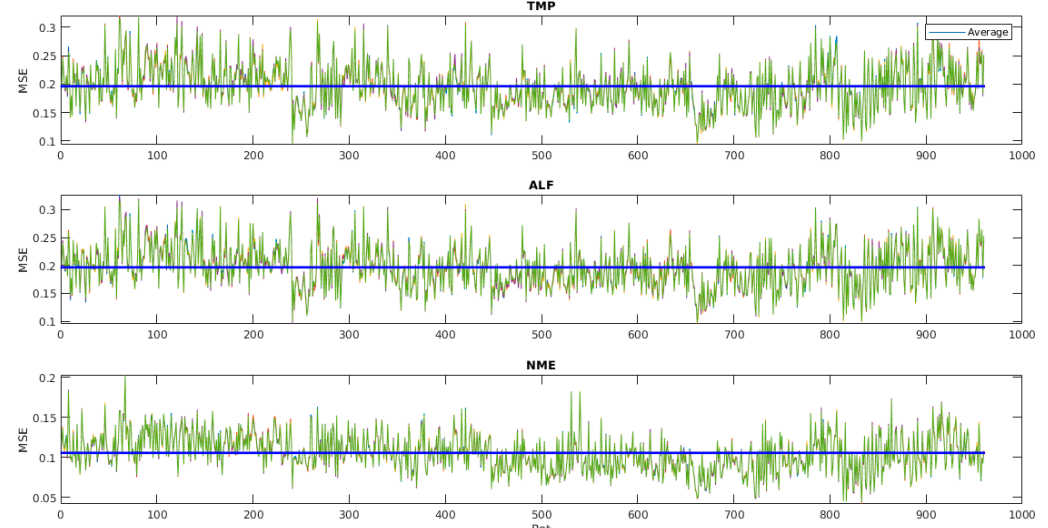

(c)

Figure 13. Cont. 


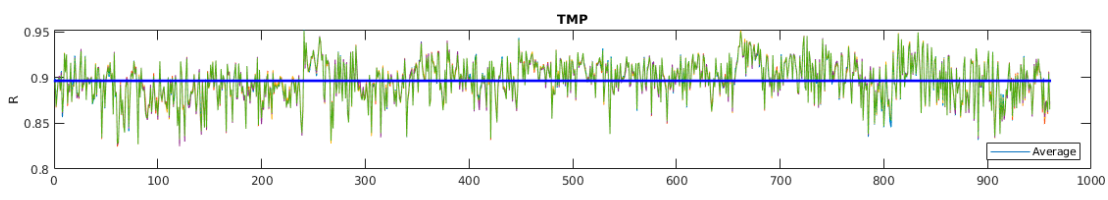

ALF

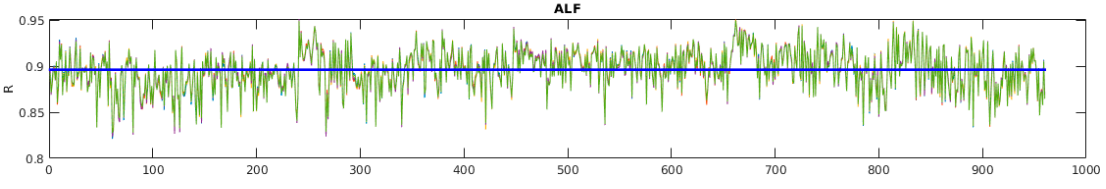

NME

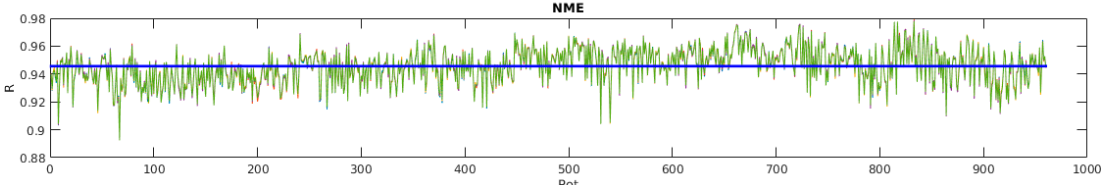

(d)

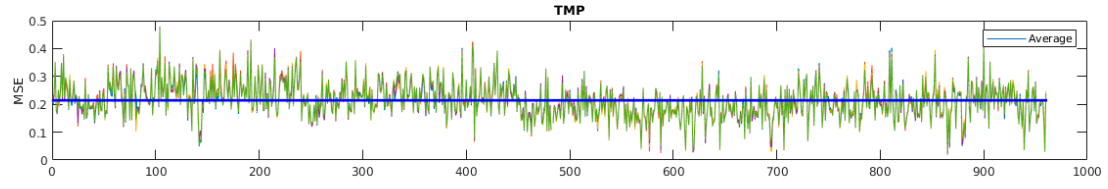

ALF

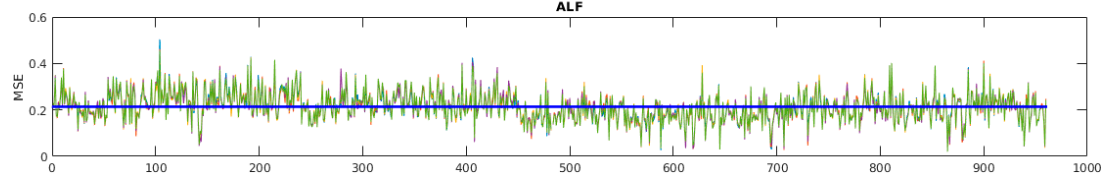

NME

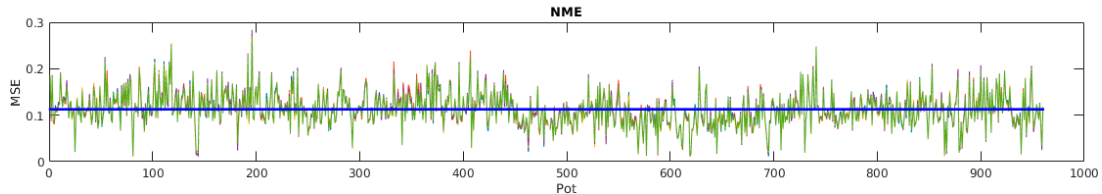

(e)

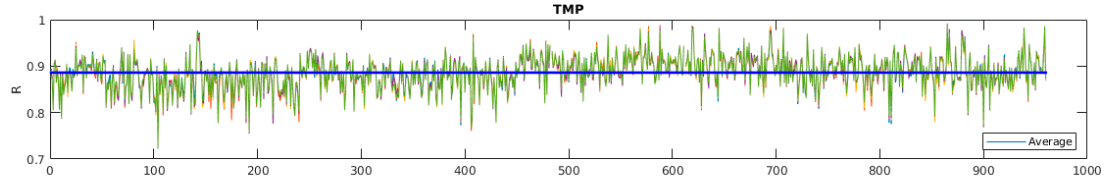

ALF

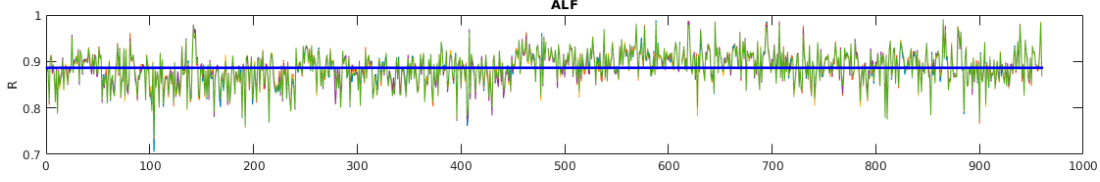

NME

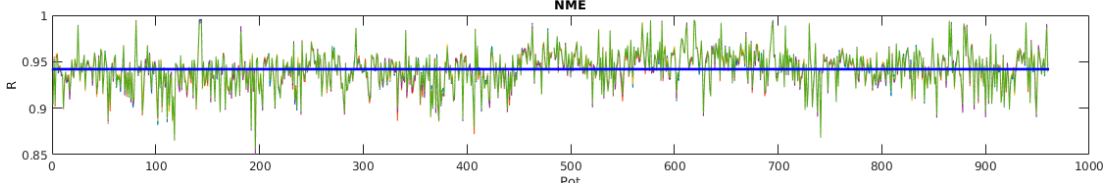

(f)

Figure 13. Mean squared error (MSE) and R values of ANN-LM based models considering the 2880 models: (a) MSE for starting point; (b) R for starting point; (c) MSE for stationary regime; (d) R for stationary regime; (e) MSE for shutdown point; and (f) R for shutdown point.

Figure 14 shows MSE and R values for the other 2880 models, considering all the characteristics and pots previously mentioned, but the ANN-BP training algorithm. It is noted that MSE and R values were bigger on average and had more variants than those of ANN-LM. It is interesting to note high variance in the results of each section.

Figure 15 shows MSE and R values for models created by all data for ANN-LM and ANN-BP. It was possible to verify higher MSE and lower R (on average) when compared to previous models. 

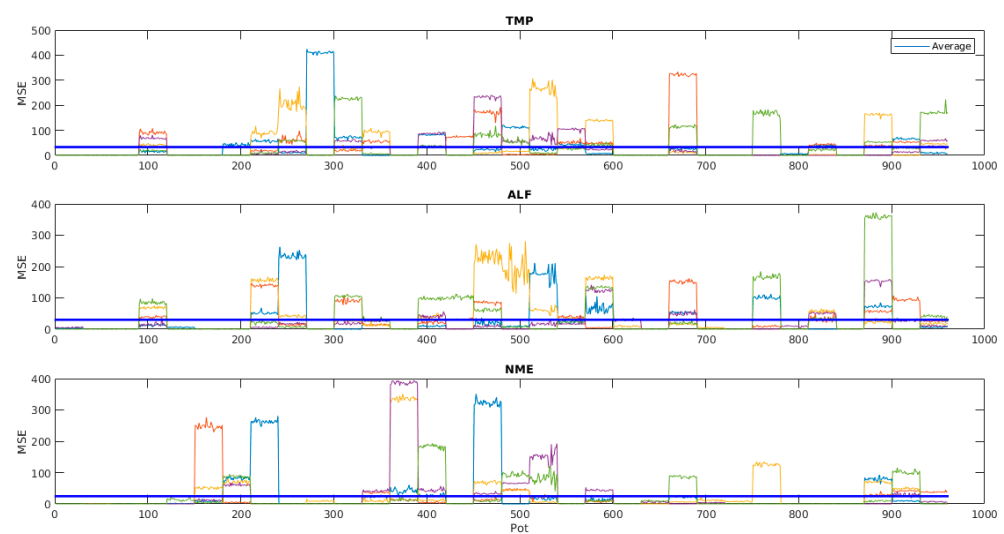

(a)
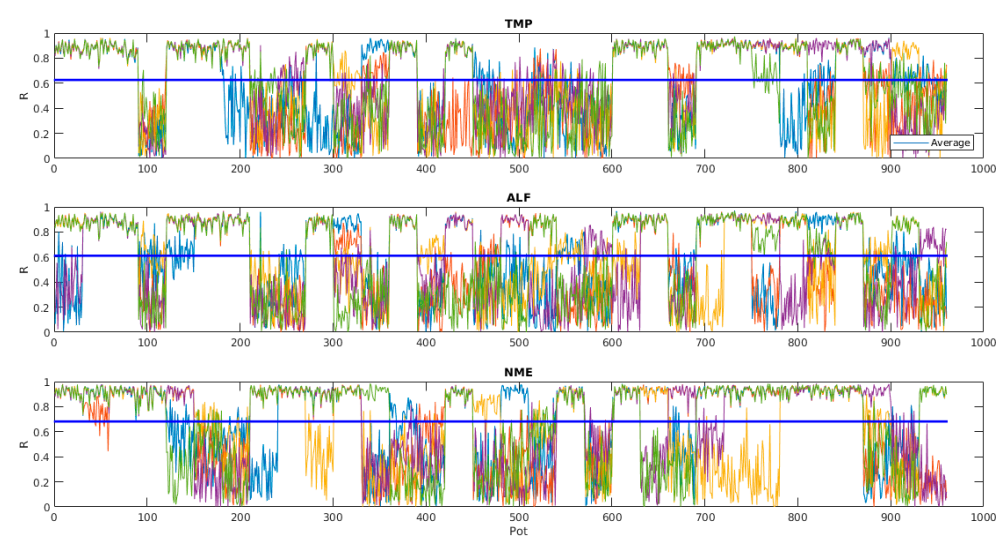

(b)
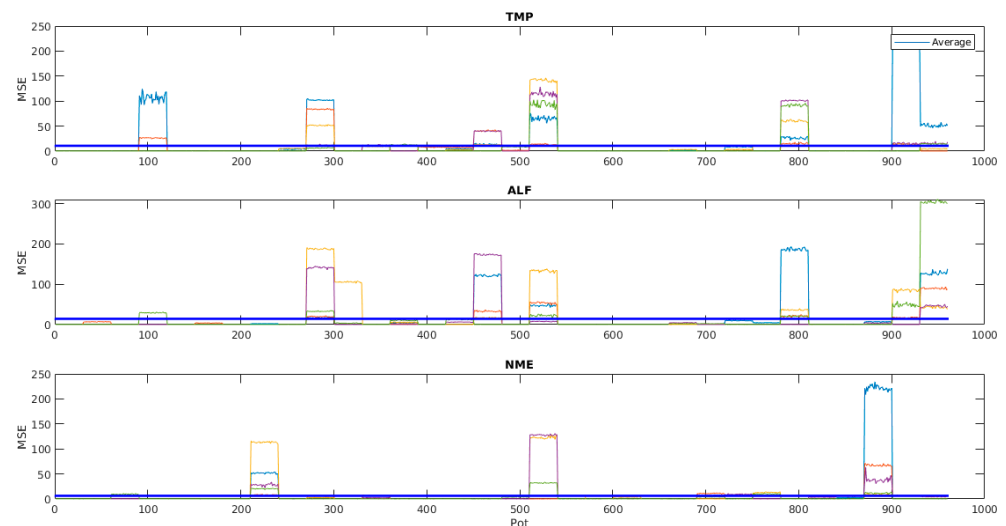

(c)
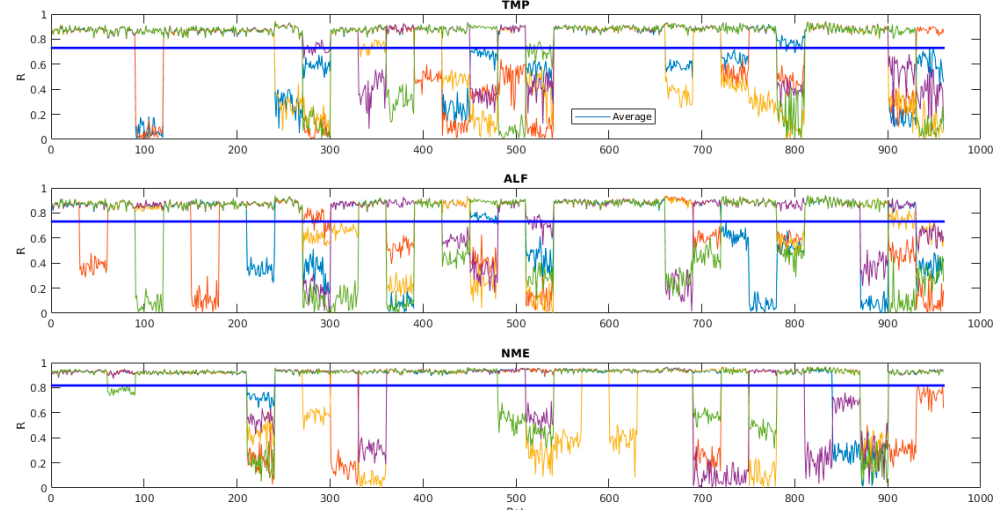

(d)

Figure 14. Cont. 

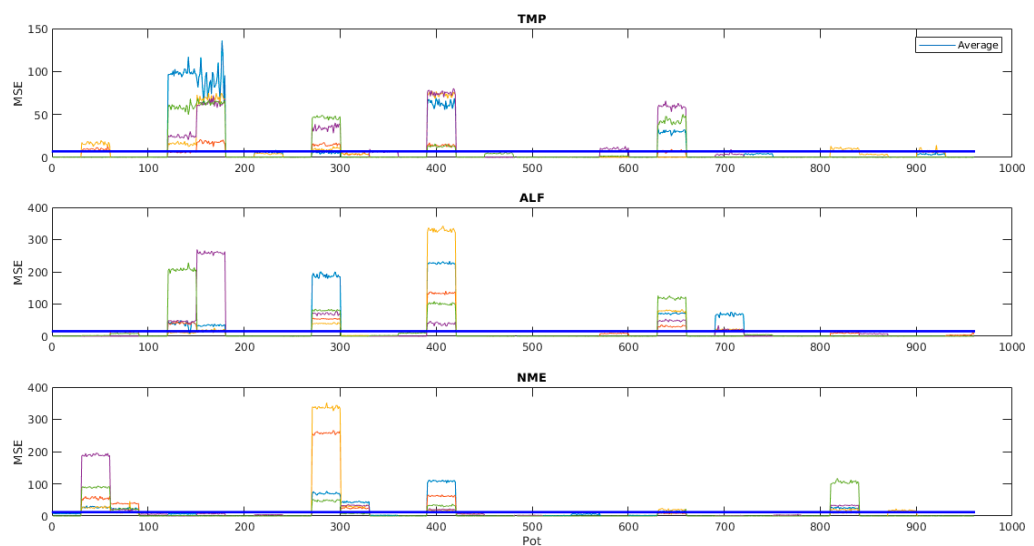

(e)
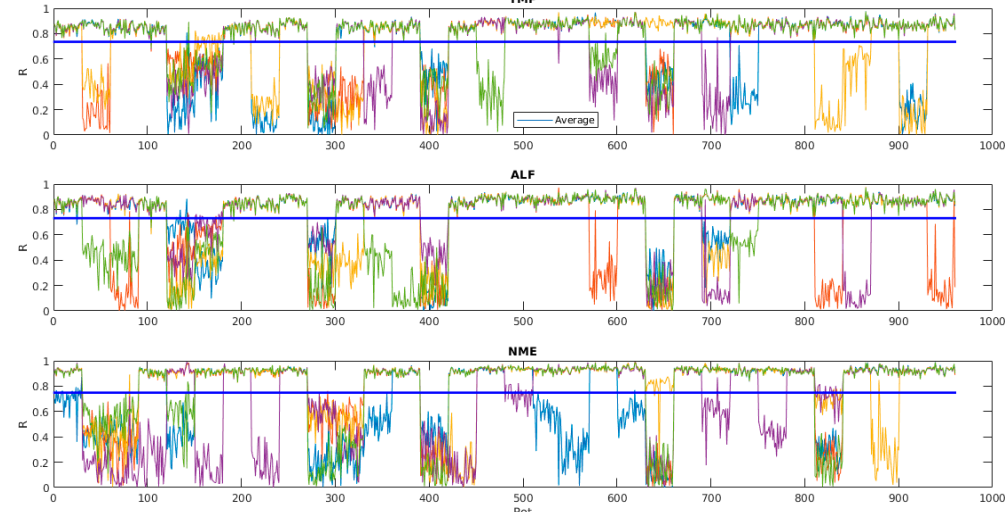

(f)

Figure 14. MSE and R values of ANN-BP-based models considering the 2880 models: (a) MSE for starting point; (b) R for starting point; (c) MSE for stationary regime; (d) R for stationary regime; (e) MSE for shutdown point; and (f) R for shutdown point.

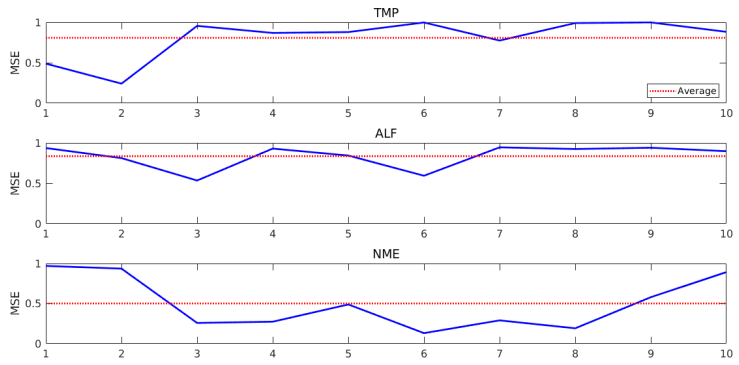

(a)
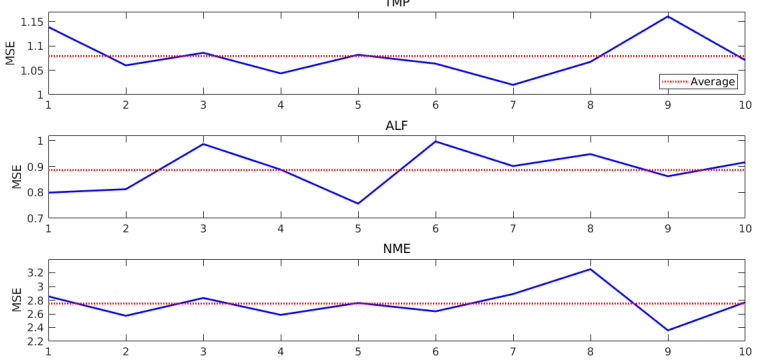

(c)

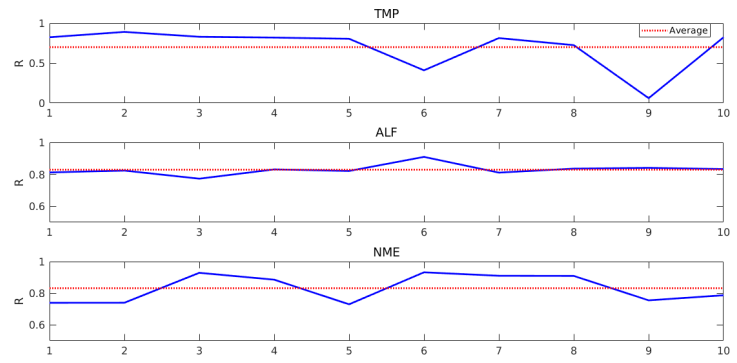

(b)
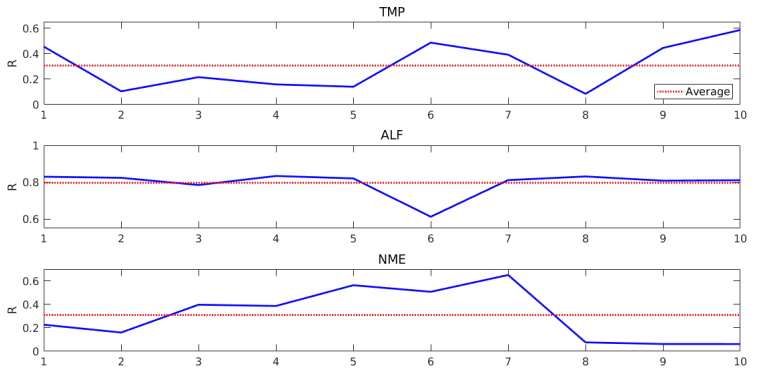

(d)

Figure 15. MSE and R values of ANN-LM- and ANN-BP-based models considering models created by all data: (a) MSE for ANN-LM; (b) R for ANN-BP; (c) MSE for ANN-BP; and (d) R for ANN-BP. 
Table 5 outlines MSE and R average (avg) and standard deviation (std) global values, besides minimum and maximum MSE and $\mathrm{R}$ values in all 5760 models. It is possible to verify that the LM algorithm generates more accurate models in all cases. The quality of the estimation is much better when LM is considered; it may be check analyzing the high values of BP's avg and std.

Table 5. Compendium of MSE and R global values considering all models.

\begin{tabular}{|c|c|c|c|c|c|c|}
\hline $\begin{array}{l}\text { Lifespan } \\
\text { Division }\end{array}$ & $\begin{array}{l}\text { ANN Training } \\
\text { Algorithm }\end{array}$ & $\begin{array}{c}\text { Output } \\
\text { Variable }\end{array}$ & MSE $_{\text {global }}$ & $\mathbf{R}_{\text {global }}$ & $\begin{array}{l}\text { MIN and } \\
\text { MAX MSE }\end{array}$ & $\begin{array}{l}\text { MIN and MAX } \\
R\end{array}$ \\
\hline \multirow{6}{*}{$\begin{array}{l}\text { Starting } \\
\text { point }\end{array}$} & \multirow{3}{*}{ LM } & TMP & $\begin{array}{l}\text { avg: } 0.182 \\
\text { std: } 0.001\end{array}$ & $\begin{array}{l}\text { avg: } 0.903 \\
\text { std: } 0.0006\end{array}$ & $0.031 ; 0.639$ & $0.623 ; 0.986$ \\
\hline & & ALF & $\begin{array}{l}\text { avg: } 0.124 \\
\text { std: } 0.002\end{array}$ & $\begin{array}{l}\text { avg: } 0.935 \\
\text { std: } 0.0009\end{array}$ & $0.015 ; 0.899$ & $0.568 ; 0.993$ \\
\hline & & NME & $\begin{array}{l}\text { avg: } 0.110 \\
\text { std: } 0.0008\end{array}$ & $\begin{array}{l}\text { avg: } 0.927 \\
\text { std: } 0.0005\end{array}$ & $0.001 ; 0.496$ & $0.727 ; 0.997$ \\
\hline & \multirow{3}{*}{$\mathrm{BP}$} & TMP & $\begin{array}{l}\text { avg: } 31.833 \\
\text { std: } 13.102\end{array}$ & $\begin{array}{l}\text { avg: } 0.618 \\
\text { std: } 0.013\end{array}$ & $0.053 ; 424.58$ & $2.5 \times 10^{-5} ; 0.973$ \\
\hline & & ALF & $\begin{array}{l}\text { avg: } 28.133 \\
\text { std: } 22.021\end{array}$ & $\begin{array}{l}\text { avg: } 0.675 \\
\text { std: } 0.017\end{array}$ & $0.029 ; 460.52$ & $0.0002 ; 0.988$ \\
\hline & & NME & $\begin{array}{l}\text { avg: } 69.322 \\
\text { std: } 23.053\end{array}$ & $\begin{array}{l}\text { avg: } 0.333 \\
\text { std: } 0.011\end{array}$ & $0.005 ; 668.16$ & $8.6 \times 10^{-6} ; 0.971$ \\
\hline \multirow{6}{*}{$\begin{array}{l}\text { Stationary } \\
\text { regime }\end{array}$} & \multirow{3}{*}{ LM } & TMP & $\begin{array}{l}\text { avg: } 0.196 \\
\text { std: } 0.0001\end{array}$ & $\begin{array}{c}\text { avg: } 0.896 \\
\text { std: } 8.5 \times 10^{-5}\end{array}$ & $0.093 ; 0.326$ & $0.821 ; 0.952$ \\
\hline & & ALF & $\begin{array}{c}\text { avg: } 0.105 \\
\text { std: } 5.5 \times 10^{-5}\end{array}$ & $\begin{array}{c}\text { avg: } 0.945 \\
\text { std: } 3.0 \times 10^{-5}\end{array}$ & $0.041 ; 0.205$ & $0.891 ; 0.979$ \\
\hline & & NME & $\begin{array}{c}\text { avg: } 0.129 \\
\text { std: } 7.9 \times 10^{-5}\end{array}$ & $\begin{array}{c}\text { avg: } 0.932 \\
\text { std: } 3.6 \times 10^{-5}\end{array}$ & $0.002 ; 0.299$ & $0.839 ; 0.982$ \\
\hline & \multirow{3}{*}{$\mathrm{BP}$} & TMP & $\begin{array}{l}\text { avg: } 12.45 \\
\text { std: } 12.84\end{array}$ & $\begin{array}{l}\text { avg: } 0.731 \\
\text { std: } 0.042\end{array}$ & $0.109 ; 310.31$ & $0.0002 ; 0.943$ \\
\hline & & ALF & $\begin{array}{l}\text { avg: } 4.84 \\
\text { std: } 11.96\end{array}$ & $\begin{array}{l}\text { avg: } 0.817 \\
\text { std: } 0.041\end{array}$ & $0.057 ; 234.28$ & $0.0005 ; 0.970$ \\
\hline & & NME & $\begin{array}{l}\text { avg: } 41.15 \\
\text { std: } 39.82\end{array}$ & $\begin{array}{l}\text { avg: } 0.526 \\
\text { std: } 0.015\end{array}$ & $0.015 ; 946.94$ & $7.7 \times 10^{-5} ; 0.972$ \\
\hline \multirow{6}{*}{$\begin{array}{c}\text { Shutdown } \\
\text { point }\end{array}$} & \multirow{3}{*}{ LM } & TMP & $\begin{array}{l}\text { avg: } 0.213 \\
\text { std: } 0.0004\end{array}$ & $\begin{array}{l}\text { avg: } 0.886 \\
\text { std: } 0.0003\end{array}$ & $0.018 ; 0.503$ & $0.705 ; 0.991$ \\
\hline & & ALF & $\begin{array}{l}\text { avg: } 0.112 \\
\text { std: } 0.0003\end{array}$ & $\begin{array}{l}\text { avg: } 0.941 \\
\text { std: } 0.0001\end{array}$ & $0.010 ; 0.283$ & $0.850 ; 0.996$ \\
\hline & & NME & $\begin{array}{l}\text { avg: } 0.184 \\
\text { std: } 0.0003\end{array}$ & $\begin{array}{l}\text { avg: } 0.897 \\
\text { std: } 0.0001\end{array}$ & $0.001 ; 0.462$ & $0.742 ; 0.998$ \\
\hline & \multirow{3}{*}{$\mathrm{BP}$} & TMP & $\begin{array}{l}\text { avg: } 11.36 \\
\text { std: } 17.93\end{array}$ & $\begin{array}{l}\text { avg: } 0.730 \\
\text { std: } 0.033\end{array}$ & $0.047 ; 342.54$ & $0.0008 ; 0.976$ \\
\hline & & ALF & $\begin{array}{l}\text { avg: } 14.34 \\
\text { std: } 27.38\end{array}$ & $\begin{array}{l}\text { avg: } 0.742 \\
\text { std: } 0.025\end{array}$ & $0.017 ; 634.69$ & $5.1 \times 10^{-5} ; 0.991$ \\
\hline & & NME & $\begin{array}{l}\text { avg: } 11.36 \\
\text { std: } 17.93\end{array}$ & $\begin{array}{l}\text { avg: } 0.581 \\
\text { std: } 0.015\end{array}$ & $0.006 ; 725.00$ & $2.3 \times 10^{-5} ; 0.990$ \\
\hline \multirow{6}{*}{ All data } & \multirow{3}{*}{ LM } & TMP & $\begin{array}{l}\text { avg: } 0.80 \\
\text { std: } 0.25\end{array}$ & $\begin{array}{l}\text { avg: } 0.70 \\
\text { std: } 0.26\end{array}$ & $0.241 ; 0.990$ & $0.061 ; 0.890$ \\
\hline & & ALF & $\begin{array}{l}\text { avg: } 0.83 \\
\text { std: } 0.15\end{array}$ & $\begin{array}{l}\text { avg: } 0.82 \\
\text { std: } 0.03\end{array}$ & $0.534 ; 0.945$ & $0.772 ; 0.909$ \\
\hline & & NME & $\begin{array}{l}\text { avg: } 0.50 \\
\text { std: } 0.32\end{array}$ & $\begin{array}{l}\text { avg: } 0.83 \\
\text { std: } 0.08\end{array}$ & $0.131 ; 0.969$ & $0.730 ; 0.932$ \\
\hline & \multirow{3}{*}{$\mathrm{BP}$} & TMP & $\begin{array}{l}\text { avg: } 1.07 \\
\text { std: } 0.04\end{array}$ & $\begin{array}{l}\text { avg: } 0.30 \\
\text { std: } 0.18\end{array}$ & $1.020 ; 1.160$ & $0.084 ; 0.585$ \\
\hline & & ALF & $\begin{array}{l}\text { avg: } 0.88 \\
\text { std: } 0.08\end{array}$ & $\begin{array}{l}\text { avg: } 0.79 \\
\text { std: } 0.06\end{array}$ & $0.756 ; 0.996$ & $0.612 ; 0.833$ \\
\hline & & NME & $\begin{array}{l}\text { avg: } 2.75 \\
\text { std: } 0.23\end{array}$ & $\begin{array}{l}\text { avg: } 0.30 \\
\text { std: } 0.22\end{array}$ & $2.359 ; 3.252$ & $0.061 ; 0.649$ \\
\hline
\end{tabular}

Comparative graphs between target values and estimated by the models were generated after the creation of estimating models and selection of the best ones. Once there were 32 models for three 
different lifespan divisions, models based on all data, three outputs (TMP, ALF, and NME), and two ANN learning algorithms, then it was necessary to select only one pot to visualize this similarity (pot 5).

Figure 16 displays comparisons for ANN-LM-based models considering non-standardized data. It verified that the models based on lifespan division (red line) estimate very well the dynamics of the process for all output variables. Models based on all data had not learned to estimate the values (green line), especially the ALF output. Next to the graphs, there were the respective MSE and R values.
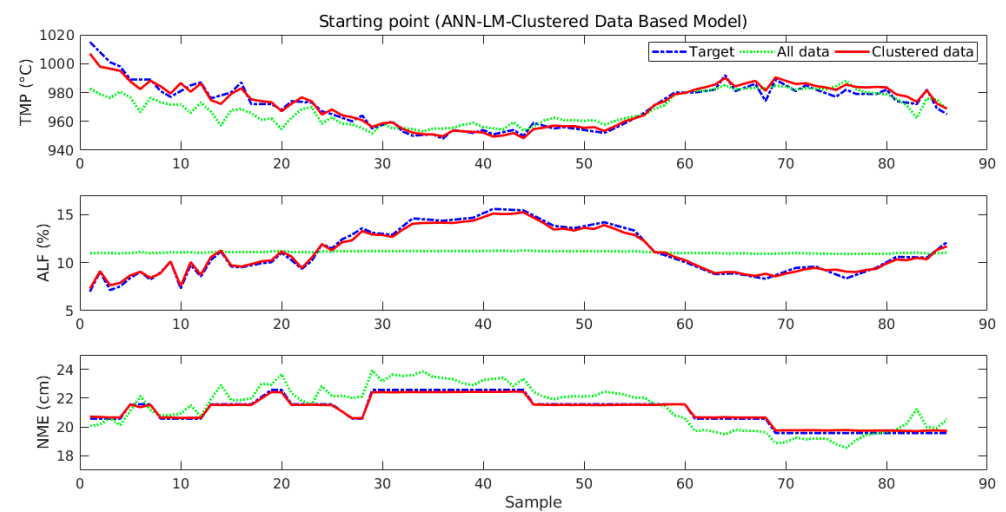

(a)
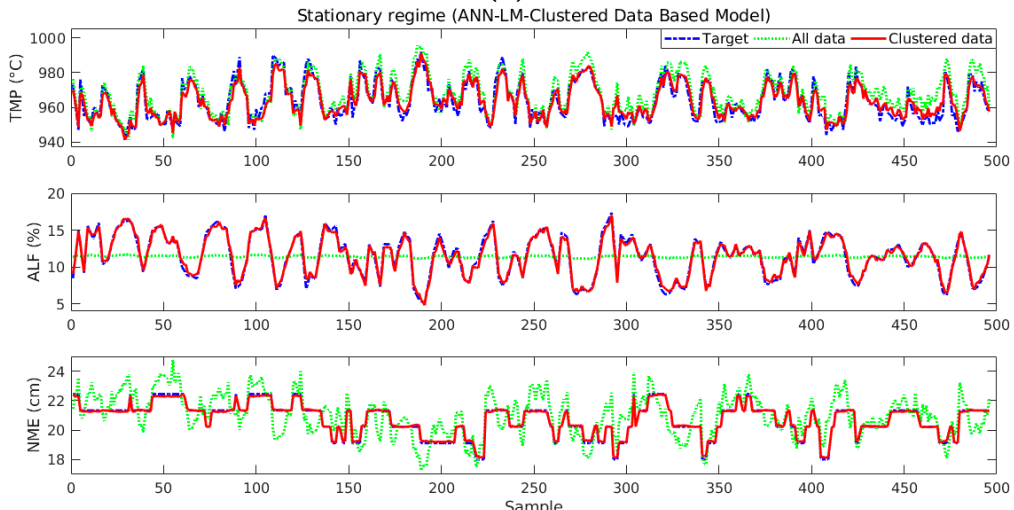

(b)
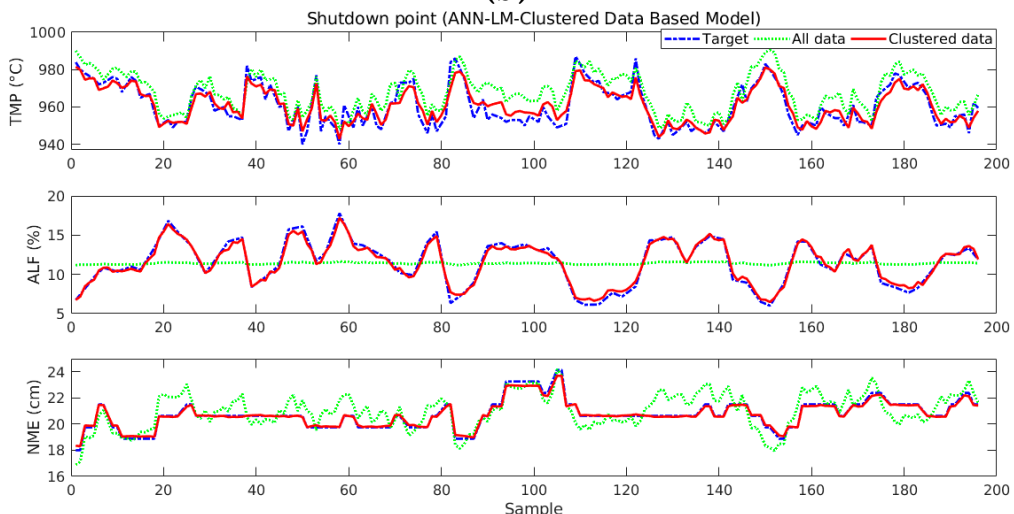

(c)

Figure 16. Comparison between target and estimated values for ANN-LM-based models and by clustered and all data: (a) starting point; (b) stationary regime; and (c) shutdown point.

Figure 17 shows comparisons for ANN-BP-based models. Estimated values also follow target values, but the accuracy is lower than the ANN-LM-based models for the most variables. When models based on all data are analyzed, it is possible to verify that they have not learned using the neural network parameters cited above. 

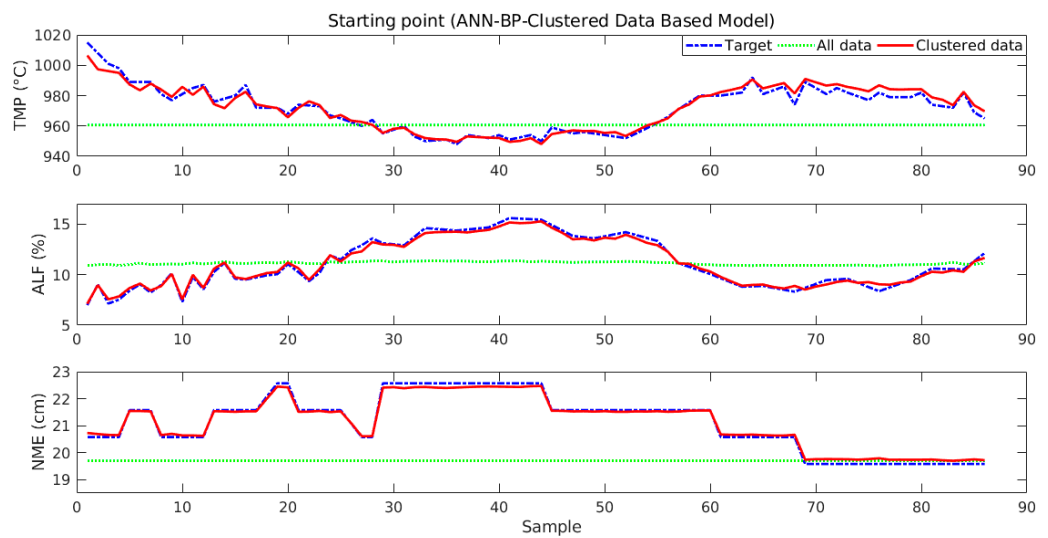

(a)

Stationary regime (ANN-BP-Clustered Data Based Model)
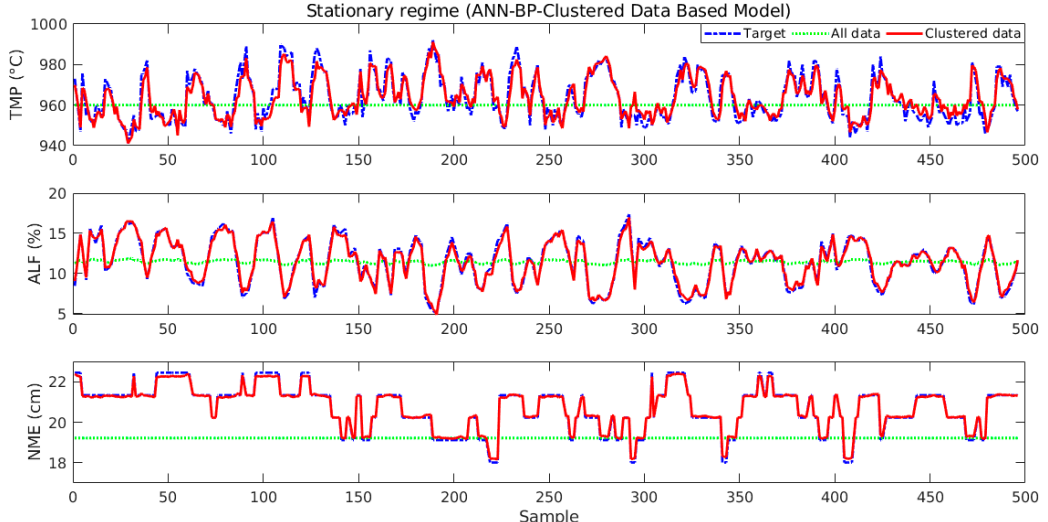

(b)
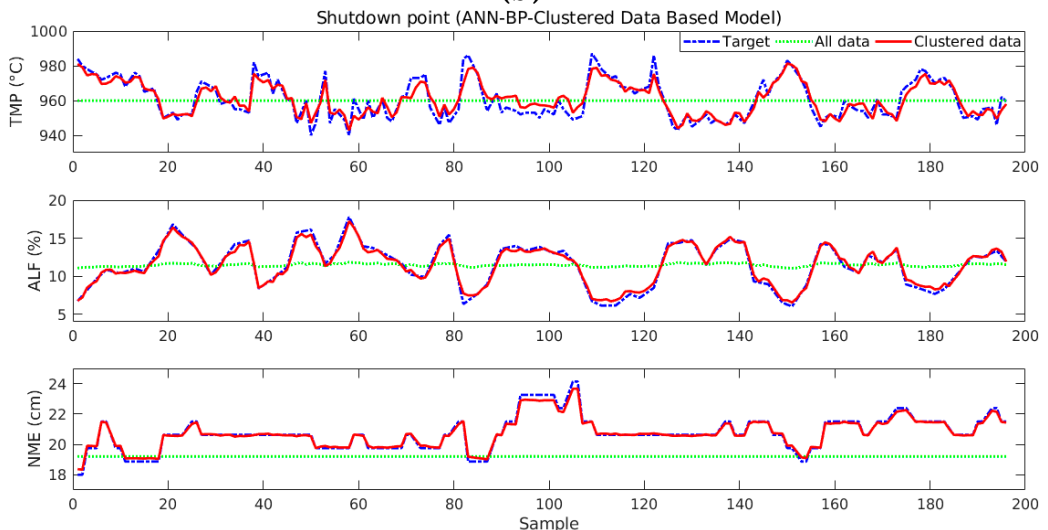

(c)

Figure 17. Comparison between target and estimated values for ANN-BP-based models and by lifespan division: (a) starting point; (b) stationary regime; and (c) shutdown point.

Table 6 displays the MSE and R values for comparisons between target and estimated values for ANN-LM, ANN-BP-based models and by clustered and all data plotted on the graphs in Figures 16 and 17. It proves the advantage of using the proposed method. It is important to remember that data used to perform these comparisons were not used in the neural net creation process. 
Table 6. MSE and R values by training algorithm, lifespan division, and data type.

\begin{tabular}{|c|c|c|c|c|}
\hline ANN Training Algorithm & Lifespan Division & Data Type & MSE & $\mathbf{R}$ \\
\hline \multirow{18}{*}{ LM } & \multirow{6}{*}{ Starting point } & \multirow{3}{*}{ Clustered } & TMP: 9.939 & TMP: 0.977 \\
\hline & & & ALF: 0.083 & ALF: 0.996 \\
\hline & & & NME: 0.014 & NME: 0.999 \\
\hline & & \multirow{3}{*}{ All data } & TMP: 73.18 & TMP: 0.809 \\
\hline & & & ALF: 5.39 & ALF: 0.867 \\
\hline & & & NME: 0.54 & NME: 0.913 \\
\hline & \multirow{6}{*}{ Stationary regime } & \multirow{3}{*}{ Clustered } & TMP: 14.37 & TMP: 0.941 \\
\hline & & & ALF: 0.179 & ALF: 0.989 \\
\hline & & & NME: 0.007 & NME: 0.999 \\
\hline & & \multirow{3}{*}{ All data } & TMP: 53.12 & TMP: 0.874 \\
\hline & & & ALF: 6.92 & ALF: 0.733 \\
\hline & & & NME: 1.00 & NME:0.905 \\
\hline & \multirow{6}{*}{ Shutdown point } & \multirow{3}{*}{ Clustered } & TMP: 15.669 & TMP: 0.940 \\
\hline & & & ALF: 0.1652 & ALF: 0.991 \\
\hline & & & NME: 0.018 & NME: 0.998 \\
\hline & & \multirow{3}{*}{ All data } & TMP: 48.58 & TMP: 0.888 \\
\hline & & & ALF: 6.92 & ALF: 0.757 \\
\hline & & & NME: 0.83 & NME: 0.839 \\
\hline \multirow{18}{*}{$\mathrm{BP}$} & \multirow{6}{*}{ Starting point } & \multirow{3}{*}{ Clustered } & TMP: 10.96 & TMP: 0.975 \\
\hline & & & ALF: 0.077 & ALF: 0.996 \\
\hline & & & NME: 0.012 & NME: 0.999 \\
\hline & & \multirow{3}{*}{ All data } & TMP: 139.13 & TMP: -0.760 \\
\hline & & & ALF: 5.19 & ALF: 0.779 \\
\hline & & & NME: 3.17 & NME: 0.818 \\
\hline & \multirow{6}{*}{ Stationary regime } & \multirow{3}{*}{ Clustered } & TMP: 14.06 & TMP: 0.942 \\
\hline & & & ALF: 0.177 & ALF: 0.989 \\
\hline & & & NME: 0.010 & NME: 0.999 \\
\hline & & \multirow{3}{*}{ All data } & TMP: 141.94 & TMP: -0.663 \\
\hline & & & ALF: 6.57 & ALF: 0.782 \\
\hline & & & NME: 3.51 & NME:0.775 \\
\hline & \multirow{6}{*}{ Shutdown point } & \multirow{3}{*}{ Clustered } & TMP: 16.624 & TMP: 0.935 \\
\hline & & & ALF: 0.158 & ALF: 0.992 \\
\hline & & & NME: 0.020 & NME: 0.998 \\
\hline & & \multirow{3}{*}{ All data } & TMP: 137.31 & TMP: -0.542 \\
\hline & & & ALF: 6.60 & ALF: 0.863 \\
\hline & & & NME: 3.53 & NME: 0.831 \\
\hline
\end{tabular}

Another results evaluation was performed analyzing residual plot in all phases, considering the best clustered based model. Figure 18 shows that the most TMP points are between $-5^{\circ} \mathrm{C}$ and $5{ }^{\circ} \mathrm{C}$, the most ALF points are between $-1 \%$ and $1 \%$, and NME points are between $-0.5 \mathrm{~cm}$ and $0.5 \mathrm{~cm}$. These error variances are perfectly acceptable by process engineer. Red lines display the std ranges. 

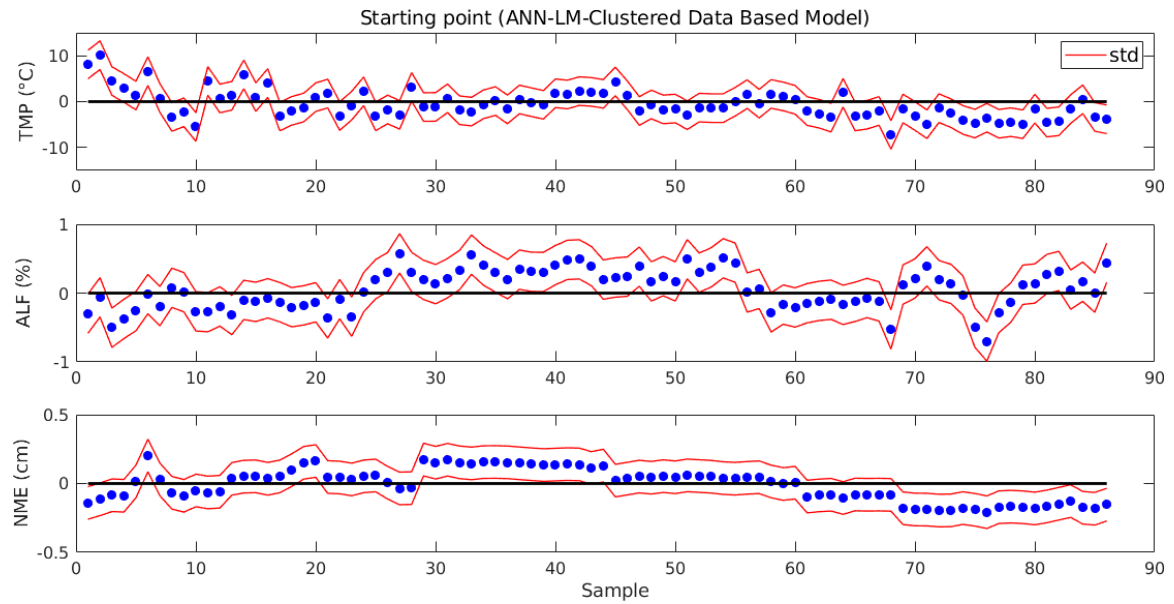

(a)
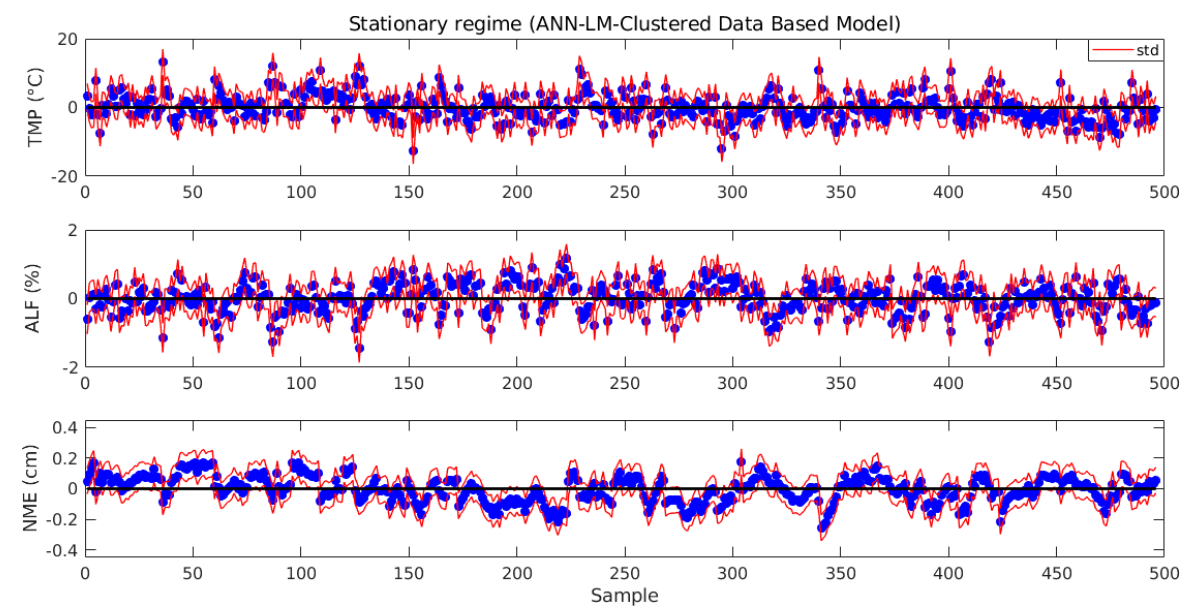

(b)
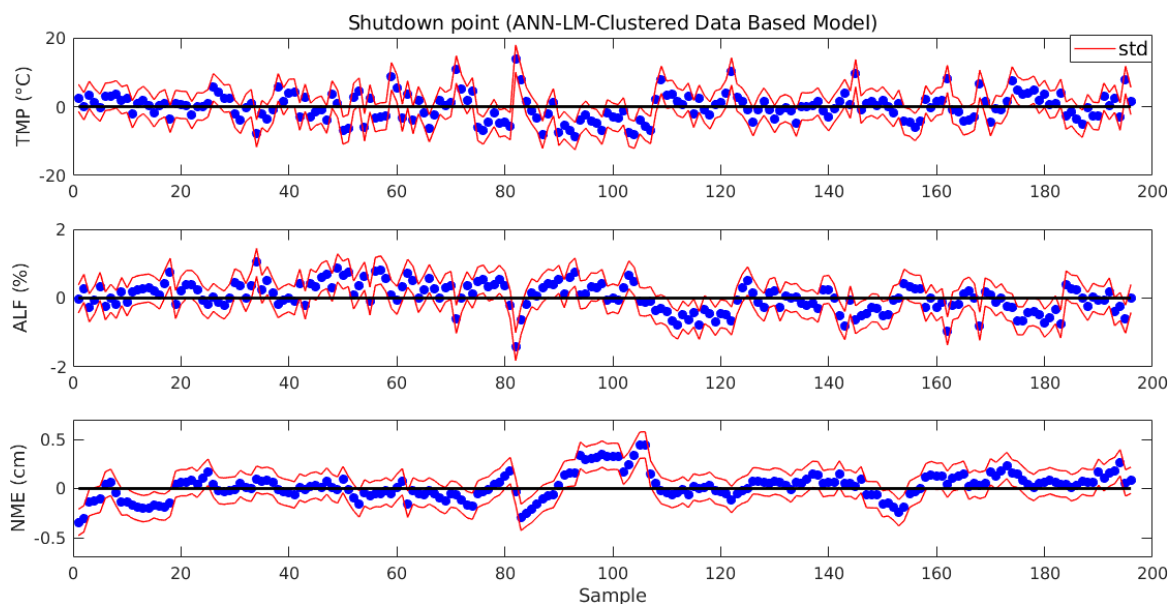

(c)

Figure 18. Residual plots: (a) starting point; (b) stationary regime; and (c) shutdown point.

\section{Conclusions}

In this work, the results of an innovative approach to create soft sensors to estimate TMP, ALF, and NME variables of primary Al production were presented. After testing different neural net topologies and considering two different training algorithms, training and testing 5940 different models, the best 
model of each output variable was selected and it was possible to ensure that these models generate high generalization power and very small errors that are fully tolerated by process engineers. In all cases, models based on section clustering and lifespan division performed more accurate estimates compared to models that do not use clustering. LM has helped to create neural networks more accurate than the BP algorithm. Besides, LM is faster for training the models.

TMP, ALF, and NME variables are the most important to control the proper functioning of the pots. The lifespan and section dataset clustering contributed to creating more specialized models in the behaviors of the respective clusters of pots, reducing errors and increasing the precision of the estimating soft sensors. ANNs have been chosen because they can generate models with a high power of generalization and they have the capability to learn the nonlinearity of the process using experimental plant data.

MATLAB ${ }^{\circledR}$ was used to develop the models, but a computer system will be created to implement the integration of soft sensors with data acquired in real time, making it possible for engineers to virtually estimate the behavior of the pots, rather than make manual or laboratory measurements. It is planned to use these soft sensors to control the pots.

Author Contributions: Conceptualization, A.M.F.d.S., C.d.M.A., and R.C.L.d.O.; methodology, A.M.F.d.S., M.A.G.d.C., A.H.d.J.B., and R.C.L.d.O.; software, A.M.F.d.S.; validation, F.M.S., C.d.M.A., and R.C.L.d.O.; formal analysis, M.A.G.d.C., N.F.N., and A.H.d.J.B., investigation, A.M.F.d.S., C.d.M.A., and R.C.L.d.O.; resources, A.M.F.d.S., R.C.L.d.O., and N.F.N.; data curation, M.A.G.d.C., N.F.N., and A.H.d.J.B.; writing一original draft preparation, A.M.F.d.S.; writing—review and editing, F.M.S., C.d.M.A., and R.C.L.d.O.; visualization, A.M.F.d.S. and F.M.S.; supervision, R.C.L.d.O. and A.H.d.J.B.; project administration, R.C.L.d.O., M.A.G.C., N.F.N., and A.H.d.J.B.

Funding: This study was financed in part by the Coordenação de Aperfeiçoamento de Pessoal de Nível Superior (Capes)-Brazil-Finance Code 001.

Acknowledgments: We appreciate the valuable contributions of the factory process engineers who helped to understand the process as a whole and the dataset. Besides, they validated the results after several meetings.

Conflicts of Interest: The authors declare no conflict of interest.

\section{References}

1. Mandin, P.; Lemoine, J.M.; Wüthrich, R.; Roustan, H. Industrial aluminium production: The Hall-Heroult process modeling. ECS Trans. 2009, 19, 1-10.

2. Grjotheim, K.; Krohn, M. Aluminium Electrolysis: Fundamentals of the Hall-Heroult Process, 3rd ed.; Aluminium Verlag Marketing \& Kommunikation GmbH: Düsseldorf, Germany, 2002.

3. Prasad, S. Studies on the Hall-Heroult aluminum electrowinning process. J. Braz. Chem. Soc. 2000, 11, 245-251. [CrossRef]

4. Fortuna, L.; Graziani, S.; Rizzo, A.; Xibilia, M.G. Soft Sensors for Monitoring and Control of Industrial Processes, 1st ed.; Springer: London, UK, 2007.

5. Forssell, U.; Ljung, L. Closed-loop identification revisited. Automatica 1999, 35, 1215-1241. [CrossRef]

6. Ogunmolu, O.P.; Gu, X.; Jiang, S.B.; Gans, N.R. Nonlinear Systems Identification Using Deep Dynamic Neural Networks. arXiv 2016, arXiv:1610.01439.

7. Pérez-Cruz, J.H.; Chairez, I.; Rubio, J.J.; Pacheco, J. Identification and control of class of non-linear systems with non-symmetric deadzone using recurrent neural networks. IET Control Theory Appl. 2014, 8, 183-192. [CrossRef]

8. Gonzalez, J.; Yu, W. Non-linear system modeling using LSTM neural networks. IFAC Papers Online 2018, 51, 485-489. [CrossRef]

9. Chen, S.; Billings, S.A.; Grant, P.M. Non-linear system identification using neural networks. Int. J. Control 1990, 51, 1191-1214. [CrossRef]

10. Haykin, S.O. Neural Networks and Learning Machines, 3rd ed.; Pearson Prentice Hall: Manitoba, ON, Canada, 2009.

11. Le Chau, N.; Nguyen, M.Q.; Dao, T.P.; Huang, S.C.; Hsiao, T.C.; Dinh-Cong, D. An effective approach of adaptive neuro-fuzzy inference system-integrated teaching learning-based optimization for use in machining optimization of S45C CNC turning. Optim. Eng. 2019, 20, 811-832. [CrossRef] 
12. Le Chau, N.; Dao, T.P.; Nguyen, V.T. An Efficient Hybrid Approach of Finite Element Method, Artificial Neural Network-Based Multiobjective Genetic Algorithm for Computational Optimization of a Linear Compliant Mechanism of Nanoindentation Tester. Math. Probl. Eng. 2018. [CrossRef]

13. Kadlec, P.; Gabrys, B.; Strandt, S. Data-driven soft sensors in the process industry. Comput. Chem. Eng. 2009, 33, 795-814. [CrossRef]

14. Lu, B.; Chiang, L. Semi-supervised online soft sensor maintenance experiences in the chemical industry. J. Process Control 2018, 67, 23-34. [CrossRef]

15. Bidar, B.; Shahraki, F.; Sadeghi, J.; Khalilipour, M.M. Soft sensor modeling based on multi-state-dependent parameter models and application for quality monitoring in industrial sulfur recovery process. IEEE Sens. J. 2018, 18, 4583-4591. [CrossRef]

16. Napier, L.F.A.; Aldrich, C. An IsaMill ${ }^{\mathrm{TM}}$ Soft Sensor based on random forests and principal component analysis. IFAC-PapersOnLine 2017, 50, 1175-1180. [CrossRef]

17. Kartik, C.K.N.; Narasimhan, S. A theoretically rigorous approach to soft sensor development using principal components analysis. Comput. Aided Chem. Eng. 2011, 29, 793-797.

18. Lin, B.; Recke, B.; Knudsen, J.K.H.; Jørgensen, S.B. A systematic approach for soft sensor development. Comput. Chem. Eng. 2007, 31, 419-425. [CrossRef]

19. Zamprogna, E.; Barolo, M.; Seborg, D.E. Optimal selection of soft sensor inputs for batch distillation columns using principal component analysis. J. Process Control 2005, 15, 39-52. [CrossRef]

20. Zheng, J.; Song, Z. Semisupervised learning for probabilistic partial least squares regression model and soft sensor application. J. Process Control 2018, 64, 123-131. [CrossRef]

21. Wei, G.; Tianhong, P. An adaptive soft sensor based on multi-state partial least squares regression. In Proceedings of the 34th Chinese Control Conference (CCC), Hangzhou, China, 28-30 July 2015; pp. 1892-1896.

22. Liu, J.; Chen, D.-S.; Lee, M.-W. Adaptive soft sensors using local partial least squares with moving window approach. Asian-Pac. J. Chem. Eng. 2012, 7, 134-144. [CrossRef]

23. Chen, K.; Castillo, I.; Chiang, L.H.; Yu, J. Soft sensor model maintenance: A case study in industrial processes. In Proceedings of the 9th International Symposium on Advanced Control of Chemical Processes, Whistler, BC, Canada, 7-10 June 2015; Volume 48, pp. 427-432.

24. Murugan, C.; Natarajan, P. Estimation of fungal biomass using multiphase artificial neural network based dynamic soft sensor. J. Microbiol. Methods 2019, 159, 5-11. [CrossRef]

25. Asteris, P.G.; Roussis, P.C.; Douvika, M.G. Feed-forward neural network prediction of the mechanical properties of sandcrete material. Sensors 2017, 17, 1344. [CrossRef]

26. Souza, F.A.A.; Araújo, R.; Matias, T.; Mendes, J. A multilayer-perceptron based method for variable selection in soft sensor design. J. Process Control 2013, 23, 1371-1378. [CrossRef]

27. Shokry, A.; Audino, F.; Vicente, P.; Escudero, G.; Moya, M.P.; Graells, M.; Espuña, A. Modeling and simulation of complex nonlinear dynamic processes using data based models: Application to photo-Fenton process. Comput. Aided Chem. Eng. 2015, 37, 191-196.

28. Gonzaga, J.C.B.; Meleiro, L.A.C.; Kiang, C.; Filho, R.M. ANN-based soft-sensor for real-time process monitoring and control of an industrial polymerization process. Comput. Chem. Eng. 2009, 33, 43-49. [CrossRef]

29. Zhao, T.; Li, P.; Cao, J. Soft sensor modeling of chemical process based on self-organizing recurrent interval type-2 fuzzy neural network. ISA Trans. 2019, 84, 237-246. [CrossRef] [PubMed]

30. Jalee, E.A.; Aparna, K. Neuro-fuzzy soft sensor estimator for benzene toluene distillation column. Procedia Technol. 2016, 25, 92-99. [CrossRef]

31. Morais, A.A., Jr.; Brito, R.P.; Sodré, C.H. Design of a soft sensor with technique NeuroFuzzy to infer the product composition of a distillation process. In Proceedings of the World Congress on Engineering and Computer Science, San Francisco, CA, USA, 22-24 October 2014.

32. Mei, C.; Yang, M.; Shu, D.; Jiang, H.; Liu, G.; Liao, Z. Soft sensor based on Gaussian process regression and its application in erythromycin fermentation process. Chem. Ind. Chem. Eng. Q. 2016, 22, 127-135. [CrossRef]

33. Abusnina, A. Gaussian Process Adaptive Soft Sensors and their Applications in Inferential Control Systems. Ph.D. Thesis, University of York, York, UK, 2014.

34. Zheng, R.; Pan, F. Soft sensor modeling of product concentration in glutamate fermentation using Gaussian process regression. Am. J. Biochem. Biotechnol. 2016, 12, 179-187. [CrossRef] 
35. Jain, P.; Rahman, I.; Kulkarni, B.D. Development of a soft sensor for a batch distillation column using support vector regression techniques. Chem. Eng. Res. Des. 2007, 85, 283-287. [CrossRef]

36. Li, Q.; Du, Q.; Ba, W.; Shao, C. Multiple-input multiple-output soft sensors based on KPCA and MKLS-SVM for quality prediction in atmospheric distillation column. Int. J. Innov. Comput. Inf. Control 2012, 8, 8215-8230.

37. Xu, W.; Fan, Z.; Cai, M.; Shi, Y.; Tong, X.; Sun, J. Soft sensing method of LS-SVM using temperature time series for gas flow measurements. Metrol. Meas. Syst. 2015, XXII, 383-392. [CrossRef]

38. Qin, S.J. Neural networks for intelligent sensors and control-Practical issues and some solutions. In Neural Systems for Control; Omidvar, O., Elliott, D.L., Eds.; Elsevier: London, UK, 1997; Chapter 8; pp. 213-234.

39. Rani, A.; Singh, V.; Gupta, J.R.P. Development of soft sensor for neural network based control of distillation column. ISA Trans. 2013, 52, 438-449. [CrossRef] [PubMed]

40. Sun, W.Z.; Wang, J.S. Elman neural network soft-sensor model of conversion velocity in polymerization process optimized by chaos whale optimization algorithm. IEEE Access 2017, 5, 13062-13076. [CrossRef]

41. Duchanoya, C.A.; Moreno-Armendáriza, M.A.; Urbina, L.; Cruz-Villar, C.A.; Calvo, H.; Rubio, J.J. A novel recurrent neural network soft sensor via a differential evolution training algorithm for the tire contact patch. Neurocomputing 2017, 235, 71-82. [CrossRef]

42. Paquet-Durand, O.; Assawarajuwan, S.; Hitzmann, B. Artificial neural network for bioprocess monitoring based on fluorescence measurements: Training without offline measurements. Eng. Life Sci. 2017, 17, 874-880. [CrossRef]

43. Conga, Q.; Yu, W. Integrated soft sensor with wavelet neural network and adaptive weighted fusion for water quality estimation in wastewater treatment process. Measurement 2018, 124, 436-446. [CrossRef]

44. Poerio, D.V.; Brown, S.D. Localized and adaptive soft sensor based on an extreme learning machine with automated self-correction strategies. J. Chemom. 2018, 1, e3088. [CrossRef]

45. Akbari, E.; Mir, M.; Vasiljeva, M.V.; Alizadeh, A.; Nilashi, M. A computational model of neural learning to predict graphene based ISFET. J. Electron. Mater. 2019, 48, 4647-4652. [CrossRef]

46. Zhao, C.; Yu, S.-h.; Miller, C.; Ghulam, M.; Li, W.-h.; Wang, L. Predicting aircraft seat comfort using an artificial neural network. Hum. Factors Ergon. Manuf. 2019, 29, 154-162. [CrossRef]

47. Shang, C.; Yang, F.; Huang, D.; Lyu, W. Data-driven soft sensor development based on deep learning technique. J. Process Control 2014, 24, 223-233. [CrossRef]

48. Yan, W.; Tang, D.; Lin, Y. A Data-driven soft sensor modeling method based on deep learning and its application. IEEE Trans. Ind. Electron. 2017, 64, 4237-4245. [CrossRef]

49. Gopakumar, V.; Tiwari, S.; Rahman, I. A deep learning based data driven soft sensor for bioprocesses. Biochem. Eng. J. 2018, 136, 28-39. [CrossRef]

50. Yuan, X.; Ou, C.; Wang, Y.; Yang, C.; Gui, W. Deep quality-related feature extraction for soft sensing modeling: A deep learning approach with hybrid VW-SAE. Neurocomputing 2019, Article in press. [CrossRef]

51. Soares, F.M.; Souza, A.M.F. Neural Network Programming with Java, 2nd ed.; Packt Publishing: Birmingham, UK, 2017.

52. Bhattacharyay, D.; Kocaefe, D.; Kocaefe, Y.; Morais, B. An artificial neural network model for predicting the $\mathrm{CO}_{2}$ reactivity of carbon anodes used in the primary aluminum production. Neural Comput. Appl. 2017, 28, 553-563. [CrossRef]

53. Piuleac, C.G.; Rodrigo, M.A.; Cañizares, P.; Curteanu, S.; Sáezb, C. Ten steps modeling of electrolysis processes by using neural networks. Environ. Model. Softw. 2010, 25, 74-81. [CrossRef]

54. Sadighi, S.; Mohaddecy, R.S.; Ameri, Y.A. Artificial neural network modeling and optimization of Hall-Héroult process for aluminum production. Int. J. Technol. 2015, 3, 480-491. [CrossRef]

55. Chermont, P.R.S.; Soares, F.M.; de Oliveira, R.C.L. Simulations on the bath chemistry variables using neural networks. Light Met. 2016, 1, 607-612.

56. Karri, V. Drilling performance prediction using general regression neural networks. Intell. Probl. Solving Methodol. Approaches 2000, 1821, 67-73.

57. Frost, F.; Karri, V. Identifying significant parameters for Hall-Héroult Process using general regression neural networks. Intell. Probl. Solving Methodol. Approaches 2010, 1821, 73-78.

58. Lima, F.A.N.; Souza, A.M.F.; Soares, F.M.; Cardoso, D.L.; Oliveira, R.C.L. Clustering aluminum smelting potlines using fuzzy C-means and K-means algorithms. Light Met. 2017, 1, 589-597.

59. Xu, M.; Isac, M.; Guthrie, R.I.L. A Numerical simulation of transport phenomena during the horizontal single belt casting process using an inclined feeding system. Metall. Mater. Trans. B 2018, 49, 1003-1013. [CrossRef] 
60. Renaudier, S.; Langlois, S.; Bardet, B.; Picasso, M.; Masserey, A. A unique suite of models to optimize pot design and performance. Light Met. 2018, 1, 541-549.

61. Baiteche, M.; Taghavi, S.M.; Ziegler, D.; Fafard, M. LES turbulence modeling approach for molten aluminium and electrolyte flow in aluminum electrolysis cell. Light Met. 2017, 1, 679-686.

62. Dupuis, M.; Jeltsch, R. On the importance of field validation in the use of cell thermal balance modeling tools. Light Met. 2016, 1, 327-332.

63. Gunasegaram, D.R.; Molenaar, D. Towards improved energy efficiency in the electrical connections of Hall-Héroult cells through finite element analysis (FEA) modeling. J. Clean. Prod. 2015, 93, 174-192. [CrossRef]

64. Totten, G.E.; MacKenzie, D.S. Introduction to aluminum. In Handbook of Aluminum, Physical Metallurgy and Processes, 1st ed.; Sverdlin, A., Ed.; CRC Press: New York, NY, USA, 2003; Volume 1, pp. 1-31.

65. Taylor, M.P.; Etzion, R.; Lavoie, P.; Tang, J. Energy balance regulation and flexible production: A new frontier for aluminum smelting. Metall. Mater. Trans. E 2014, 1, 292-302. [CrossRef]

66. Chen, J.J.J.; Taylor, M.P. Control of temperature and aluminium fluoride in aluminium reduction. Alum. Int. J. Ind. Res. Appl. 2005, 81, 678-682.

67. Haupin, W. The influence of additives on Hall-Héroult bath properties. J. Miner. Metals Mater. Soc. (TMS)-JOM 1991, 43, 28-34. [CrossRef]

68. Taylor, M.P.; Chen, J.J.J.; Young, B.R. Control for Aluminum Production and Other Processing Industries; CRC Press Taylor \& Francis Group: Boca Raton, FL, USA, 2014.

69. Lumley, R. Fundamentals of Aluminium Metallurgy: Production, Processing and Applications, 1st ed.; Elsevier: Sawston, Cambridge, UK, 2010.

70. Chen, X.; Jie, L.; Zhang, W.; Zou, Z.; Ding, F.; Liu, Y.; Li, Q. The development and application of data warehouse and data mining in aluminum electrolysis control systems. TMS Light Met. 2006, 1, 515-519.

71. Ugarte, B.; Hajji, A.; Pellerina, R.; Artibab, A. Development and integration of a reactive real-time decision support system in the aluminum industry. Eng. Appl. Artif. Intell. 2009, 22, 897-905. [CrossRef]

72. Pereira, V.G. Automatic Control of AlF3 Addition in Aluminum Reduction Pots Using Fuzzy Logic. Master's Thesis, Postgraduate Program in Electrical Engineering, Federal University of Pará, Belém, Brazil, 2005. (In Portuguese)

73. Majid, N.A.A.; Taylor, M.P.; Chen, J.J.J.; Stam, M.A.; Mulder, A.; Brent, Y.R. Aluminium process fault detection by multiway principal component analysis. Control Eng. Pract. 2011, 19, 367-379. [CrossRef]

74. Braga, C.A.P.; Netto, J.V.F. A dynamic state observer to control the energy consumption in aluminium production cells. Syst. Sci. Control Eng. 2016, 4, 307-319. [CrossRef]

75. Mares, E.; Sokolowski, J.H. Artificial intelligence-based control system for the analysis of metal casting properties. J. Achiev. Mater. Manuf. Eng. 2010, 40, 149-154.

76. Du, Y.-C.; Stephanus, A. Levenberg-Marquardt neural network algorithm for degree of arteriovenous fistula stenosis classification using a dual optical photoplethysmography sensor. Sensors 2018, 18, 2322. [CrossRef] [PubMed]

77. Hagan, M.T.; Menhaj, M.B. Training feedforward networks with the Marquardt algorithm. IEEE Trans. Neural Netw. 1994, 5, 989-993. [CrossRef] [PubMed]

78. Feng, J.; Sun, Q.; Li, Z.; Sun, Z.; Jia, K. Back-propagation neural network-based reconstruction algorithm for diffuse optical tomography. J. Biomed. Opt. 2018, 24, 051407. [CrossRef] [PubMed]

79. Rumelhart, D.E.; Hinton, G.E.; Williams, R.J. Learning representations by back-propagating errors. Nature 1986, 323, 533-536. [CrossRef]

(C) 2019 by the authors. Licensee MDPI, Basel, Switzerland. This article is an open access article distributed under the terms and conditions of the Creative Commons Attribution (CC BY) license (http://creativecommons.org/licenses/by/4.0/). 